\title{
Base-Catalyzed Three-Component Reaction of $\alpha$-Cyanoacetates with Chalcones and Elemental Sulfur: Access to 2-Aminothiophenes Unobtainable via the Gewald Reaction
}

\author{
Thanh Binh Nguyen, ${ }^{* a}$ Dinh Hung Mac, ${ }^{* b}$ and Pascal Retailleau ${ }^{\mathrm{a}}$ \\ a Institut de Chimie des Substances Naturelles, CNRS UPR 2301, Université Paris-Sud, Université \\ Paris-Saclay, 1 avenue de la Terrasse, 91198 Gif-sur-Yvette, France \\ b Faculty of chemistry, VNU University of Science, Vietnam National University in Hanoi, 19 Le \\ Thanh Tong, Hanoi, Viet Nam \\ E-mail: thanh-binh.nguyen@cnrs.fr; macdinhhung@hus.edu.vn
}

\section{Supporting Information}




\section{Table of content}

Crystallographic data collection, structure determination and refinement ..................S3

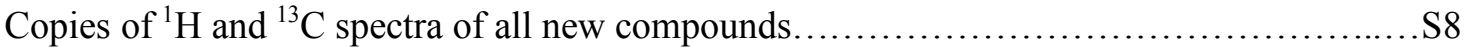




\section{Crystallographic data collection, structure determination and refinement}

$\mathrm{X}$-ray diffraction data for the three compounds that crystallized in saturated $\mathrm{CDCl}_{3}$ solutions were recorded at the $K \alpha$ Mo wavelength using a microfocused sealed tube generator (a RIGAKU XtaLabPro diffractometer equipped with a double-bounce confocal Max-Flux ${ }^{\circledR}$ multilayer optic and a HPAD PILATUS3R 200K detector for 3aab and a BRUKER APEX-II CCD for compounds 3aag and 3aca). The datasets were processed respectively using CrysAlisPro 1.171.39.46 ${ }^{[1]}$ implementing the SCALE3 ABSPACK scaling algorithm for the empirical absorption correction using spherical harmonics for 3aab and the APEX2 program $^{[2]}$ implementing the SADABS-2016/2 (Bruker,2016/2) for the two other ones. Additionally, crystals 3aag and 3aca were maintained at low temperature (273K) in a $\mathrm{LN}_{2}$ stream during data collection. The three structures were readily solved by intrinsic phasing methods (SHELXT program), ${ }^{[2]}$ then refined by full-matrix least-squares methods on $F^{2}$ using SHELX-L. ${ }^{[3]}$ All non-hydrogen atoms of the molecules of interest improved by anisotropic refinement. Most of the $\mathrm{H}$ atoms were identified in Fourier difference maps. Aromatic $\mathrm{H}$ atoms bound to carbon atoms were positioned geometrically and refined with $U_{\text {iso }}$ set to $1.2 U_{\text {eq }}(\mathrm{C})$ of the parent carbon atom as well as for $\mathrm{CH}_{2}$ group. Methyl $\mathrm{H}$ atoms were also idealized and included as rigid groups allowed to rotate, but not tip, and refined with $U_{\text {iso }}$ set to $1.5 U_{\text {eq }}(\mathrm{C})$ of the parent carbon atom. Positions of $\mathrm{H}$ atoms borne by nitrogens were refined using $\mathrm{N}-\mathrm{H}$ distance restraints of 0.87 (2) $\AA$ and with $U_{\text {iso }}$ set to $1.2 U_{\text {eq }}(\mathrm{N})$. In $\mathbf{3 a a b}$, the ethyl carboxylate chain displays some disorder modeled by two close orientations in a 0.56(1):0.44(1) occupancy ratio and by application of rigid bond and fragments restraints as well as $U_{\text {iso }} / U_{\text {aniso }}$ restraints (DELU). In 3aag, the dynamic disorder of the benzyl atoms was treated with rigid body restraints. It is noteworthy that the centroid distance between benzoyl ring and the phenyl one at the 5 and 4 respective substitution position of the thiophene moiety increases from $3.66 \AA$ in $\mathbf{3 a a g}$ to $3.96 \AA$ in $\mathbf{3 a a b}$ with a value of $3.71 \AA$ in 3aca (see figure 4 ). The centroid distance between the phenyl at position 4 and the $\mathrm{N}$-benzyl at position 3 is much longer than the previous ones (4.27 A).

Crystal data, data collection and structure refinement details are summarized in Table 1.

CCDC 2062860-2062862 (compounds 3aab, 3aag and 3aca respectively) contain the supplementary crystallographic data for this paper. These data can be obtained free of charge from The Cambridge Crystallographic Data Centre via www.ccdc.cam.ac.uk/data_request/cif.

References

1 Rigaku OD (2015). CrysAlis PRO. Rigaku Oxford Diffraction, Yarnton, Oxfordshire, England. 
2 Bruker (2012). APEX2. Bruker AXS Inc., Madison, Wisconsin, USA.

3 Bruker (2016). SADABS-2016/2. Bruker AXS Inc., Madison, Wisconsin, USA.

4 Sheldrick, G. M. (2015). Acta Crystallogr., C71, 3-8.

5 Sheldrick, G. M. (2015). Acta Crystallogr., A71, 3-8. 
Table S1 Crystal data, data collection and structure refinement details for 3aab, 3aag and 3aca.

\begin{tabular}{|c|c|c|c|}
\hline Compound & $\begin{array}{c}\text { ethyl 2-amino-5- } \\
\text { benzoyl-4- } \\
\text { phenylthiophene-3- } \\
\text { carboxylate }\end{array}$ & $\begin{array}{l}\text { 2-amino-5-benzoyl- } \\
\qquad \text {-benzyl-4- } \\
\text { phenylthiophene-3- } \\
\text { carboxamide }\end{array}$ & \begin{tabular}{|c|} 
tert-butyl 2-amino-5- \\
benzoyl-4-(3- \\
chlorophenyl)thiophene- \\
3-carboxylate
\end{tabular} \\
\hline & 3aab & 3aag & 3aca \\
\hline Empirical formula & $\mathrm{C}_{20} \mathrm{H}_{17} \mathrm{NO}_{3} \mathrm{~S}$ & $\mathrm{C}_{25} \mathrm{H}_{20} \mathrm{~N}_{2} \mathrm{O}_{2} \mathrm{~S}$ & $\mathrm{C}_{22} \mathrm{H}_{20} \mathrm{ClNO}_{3} \mathrm{~S}$ \\
\hline Formula weight & 351.4 & 412.49 & 413.90 \\
\hline Temperature (K) & $293(2)$ & $273(2)$ & $273(2)$ \\
\hline Wavelength $(\AA)$ & 0.71073 & 0.71073 & 0.71073 \\
\hline $\begin{array}{l}\text { Crystal system, } \\
\text { space group }\end{array}$ & $\begin{array}{l}\text { Orthorhombic, } \\
\qquad P \text { bca }\end{array}$ & $\begin{array}{l}\text { Monoclinic, } \\
\qquad P 2_{1} / \mathrm{n}\end{array}$ & $\begin{array}{l}\text { Monoclinic, } \\
\qquad P 2_{1} / \mathrm{n}\end{array}$ \\
\hline $\begin{array}{l}\text { Unit cell dimensions } \mid \mathrm{a}(\AA) \\
\qquad \begin{array}{l}\mid \mathrm{b} \\
\mid \mathrm{c} \\
\mid \beta\left(^{\circ}\right)\end{array}\end{array}$ & $\begin{array}{c}8.3501(7) \\
19.2455(11) \\
22.7414(19) \\
90\end{array}$ & $\begin{array}{l}16.7320(6) \\
6.0451(3) \\
21.0937(8) \\
104.482(1)\end{array}$ & $\begin{array}{l}12.5271(5) \\
9.1886(3) \\
18.1514(7) \\
96.142(2)\end{array}$ \\
\hline Volume $\left(\AA^{3}\right)$ & $3654.6(5)$ & $2065.77(15)$ & $2077.35(13)$ \\
\hline $\begin{array}{l}\mathrm{Z} \\
\text { Calculated density }\left(\mathrm{Mg} / \mathrm{m}^{3}\right)\end{array}$ & $\begin{array}{c}8, \\
1.277\end{array}$ & $\begin{array}{c}4, \\
1.326\end{array}$ & $\begin{array}{c}4, \\
1.323\end{array}$ \\
\hline Absorption coefficient $\left(\mathrm{mm}^{-1}\right)$ & 0.195 & 0.181 & 0.307 \\
\hline $\mathrm{F}(000)$ & 1472 & 864 & 864 \\
\hline
\end{tabular}




\begin{tabular}{|c|c|c|c|c|}
\hline \multicolumn{2}{|c|}{ Crystal size $(\mathrm{mm})$} & $0.41 \times 0.10 \times 0.03$ & $0.35 \times 0.31 \times 0.19$ & $0.38 \times 0.25 \times 0.218$ \\
\hline \multicolumn{2}{|c|}{$\theta$ range for data collection $\left(^{\circ}\right)$} & 3.584 to 29.682 & 3.750 to 29.435 & 2.755 to 26.022 \\
\hline \multicolumn{2}{|l|}{ Limiting indices } & $\begin{array}{l}-9 \leq \mathrm{h} \leq 9 \\
-22 \leq \mathrm{k} \leq 22 \\
-27 \leq 1 \leq 27\end{array}$ & $\begin{array}{l}-20 \leq \mathrm{h} \leq 20 \\
-7 \leq \mathrm{k} \leq 7 \\
-26 \leq 1 \leq 24\end{array}$ & $\begin{array}{l}-20 \leq \mathrm{h} \leq 20 \\
-7 \leq \mathrm{k} \leq 7 \\
-26 \leq 1 \leq 24\end{array}$ \\
\hline \multicolumn{2}{|c|}{ Reflections collected / unique } & $\begin{array}{c}32759 / 3215 \\
0.062\end{array}$ & $\begin{array}{c}31792 / 4075 \\
0.064\end{array}$ & $29897 / 40770.0403$ \\
\hline \multicolumn{2}{|c|}{ Completeness to $\theta_{\text {full }}(\%)$} & 99.8 & 99.9 & 99.6 \\
\hline \multicolumn{2}{|c|}{ Absorption correction } & \multicolumn{3}{|c|}{ Semi-empirical from equivalents } \\
\hline \multicolumn{2}{|c|}{ Max. and min. transmission } & 1.000 and 0.167 & 0.746 and 0.692 & 0.856 and 0.523 \\
\hline \multicolumn{2}{|c|}{ Refinement method } & \multicolumn{3}{|c|}{ Full-matrix least-squares on $F^{2}$} \\
\hline \multicolumn{2}{|c|}{ Data / restraints / parameters } & $3210 / 169 / 280$ & $4075 / 48 / 280$ & $4078 / 2 / 262$ \\
\hline \multicolumn{2}{|c|}{ Goodness-of-fit on $F^{2}$} & 1.003 & 1.089 & 1.029 \\
\hline $\begin{array}{l}\text { Final R indices } \\
[I>2 \sigma I)]\end{array}$ & $\begin{array}{l}\text { R1 } \\
\text { wR2 }\end{array}$ & $\begin{array}{l}0.0459, \\
0.1110\end{array}$ & $\begin{array}{l}0.0587, \\
0.1114\end{array}$ & $\begin{array}{l}0.0422, \\
0.0951\end{array}$ \\
\hline $\begin{array}{l}\mathrm{R} \text { indices } \\
\text { (all data) }\end{array}$ & $\begin{array}{l}\text { R1 } \\
\text { wR2 }\end{array}$ & $\begin{array}{l}0.0758, \\
0.1326\end{array}$ & $\begin{array}{l}0.0729, \\
0.1191\end{array}$ & $\begin{array}{l}0.0588, \\
0.1051\end{array}$ \\
\hline \multicolumn{2}{|c|}{ Largest $\Delta$ peak and hole $\left(\mathrm{e} . \AA^{-3}\right)$} & 0.123 and -0.176 & 0.363 and -0.225 & 0.219 and -0.274 \\
\hline \multicolumn{2}{|c|}{ CCDC deposit number } & 2062860 & 2062861 & 2062862 \\
\hline
\end{tabular}




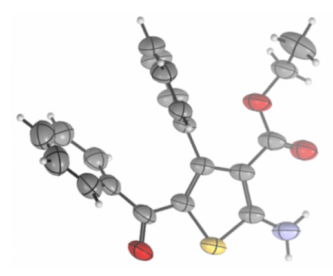

Figure S1. Ortep view of the main conformer of 3aab in the asymmetric unit cell. Displacement ellipsoids are shown at the $30 \%$ probability level. $\mathrm{H}$ atoms are presented as small spheres of arbitrary radius.

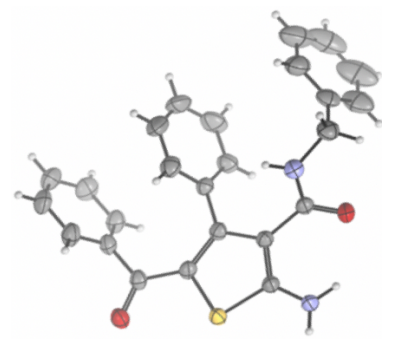

Figure S2. Ortep view of 3aag. Displacement ellipsoids are shown at the $50 \%$ probability level. H atoms are presented as small spheres of arbitrary radius

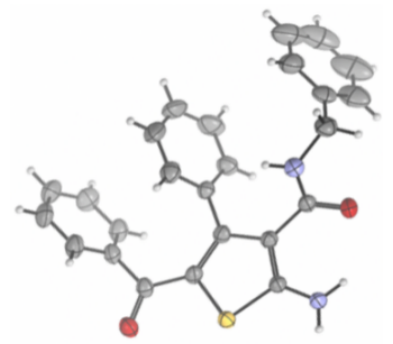

Figure S3. Ortep view of 3aca. Displacement ellipsoids are shown at the 50\% probability level. H atoms are presented as small spheres of arbitrary radius

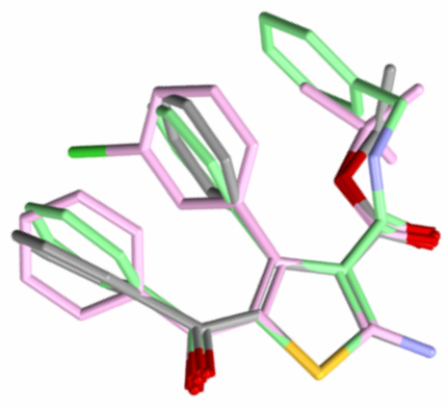

Figure S4. Overlay diagram of 3aab, 3aag (carbons in green), and 3aca (in pink) upon the common thiophene moiety. 


\section{Copies of ${ }^{1} \mathrm{H}$ and ${ }^{13} \mathrm{C}$ spectra of all new compounds}

tert-Butyl 2-amino-5-benzoyl-4-phenylthiophene-3-carboxylate (3aaa)

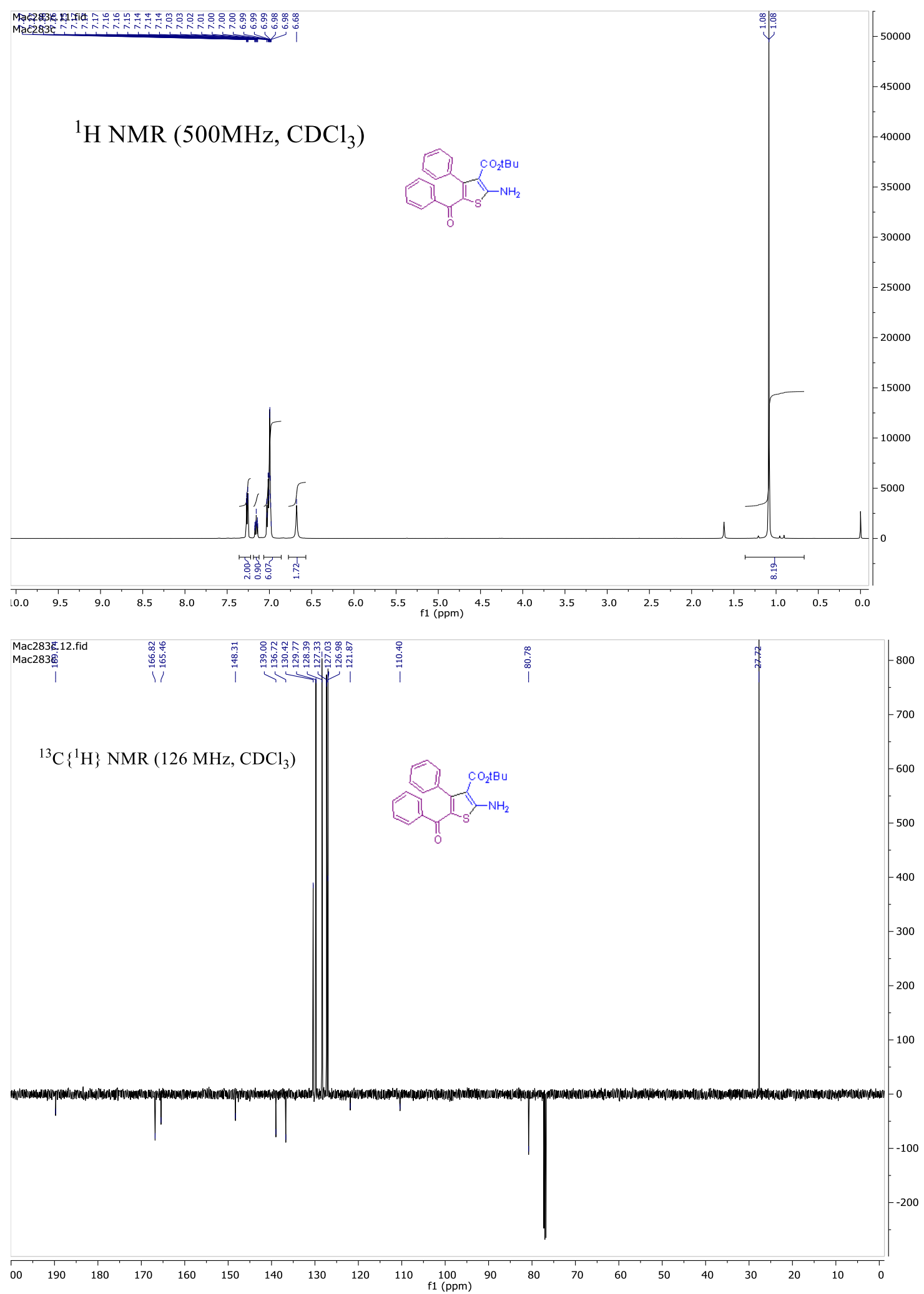


Ethyl 2-amino-5-benzoyl-4-phenylthiophene-3-carboxylate (3aab)
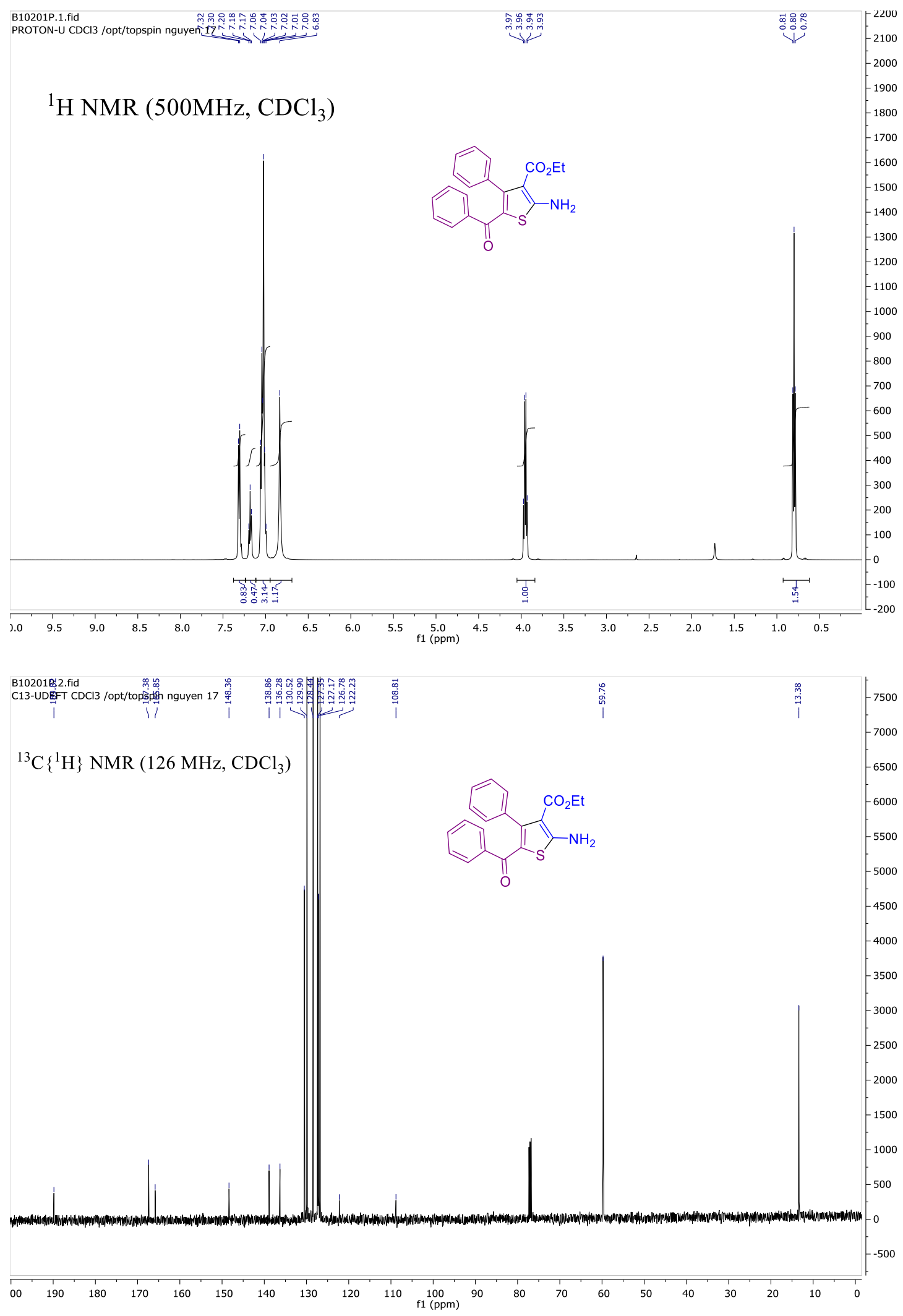
tert-Butyl 2-amino-5-(4-nitrobenzoyl)-4-phenylthiophene-3-carboxylate (3aba)

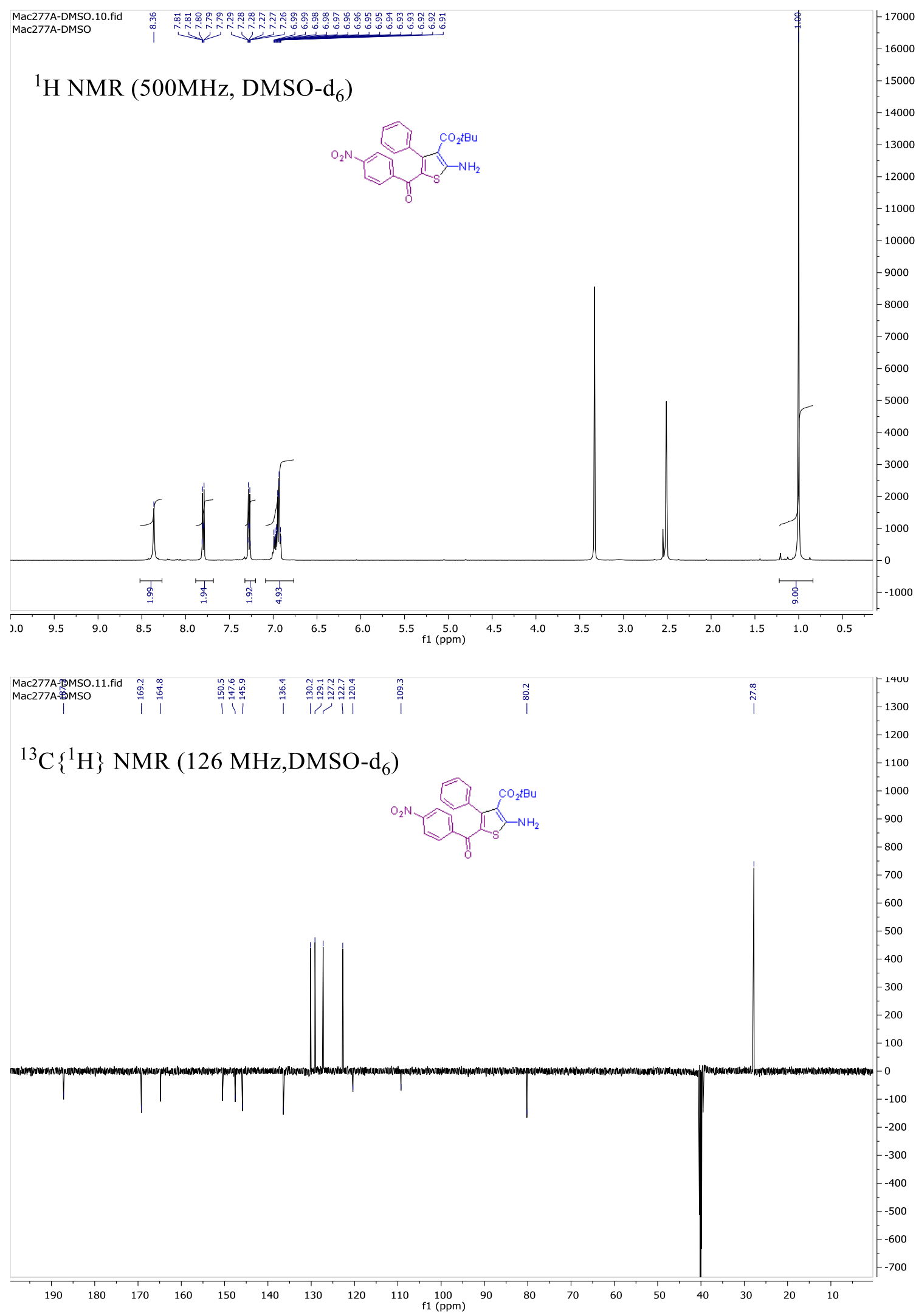


tert-Butyl 2-amino-5-benzoyl-4-(4-nitrophenyl)thiophene-3-carboxylate (3baa)

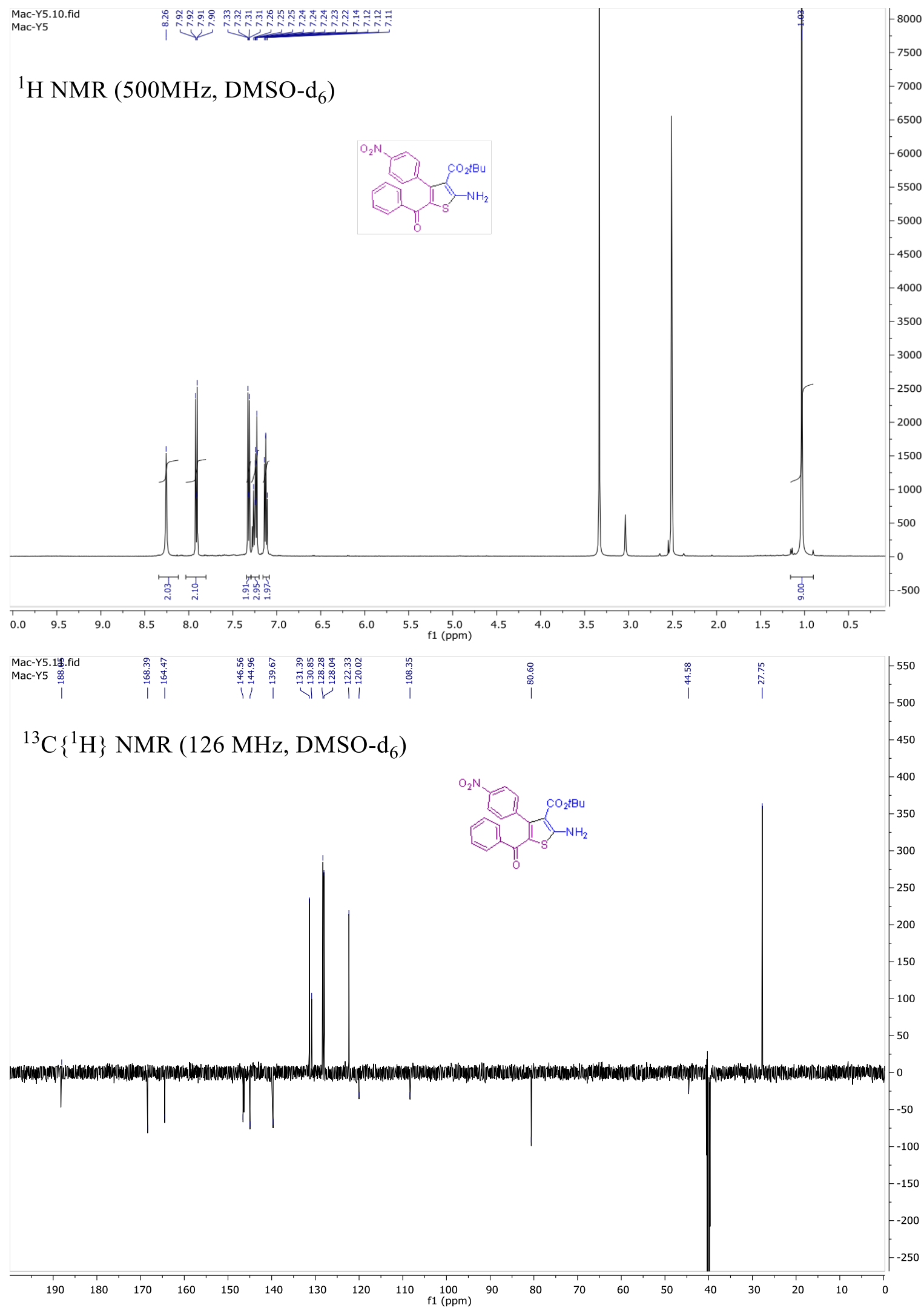


tert-Butyl 2-amino-5-(3-chlorobenzoyl)-4-phenylthiophene-3-carboxylate (3aca)
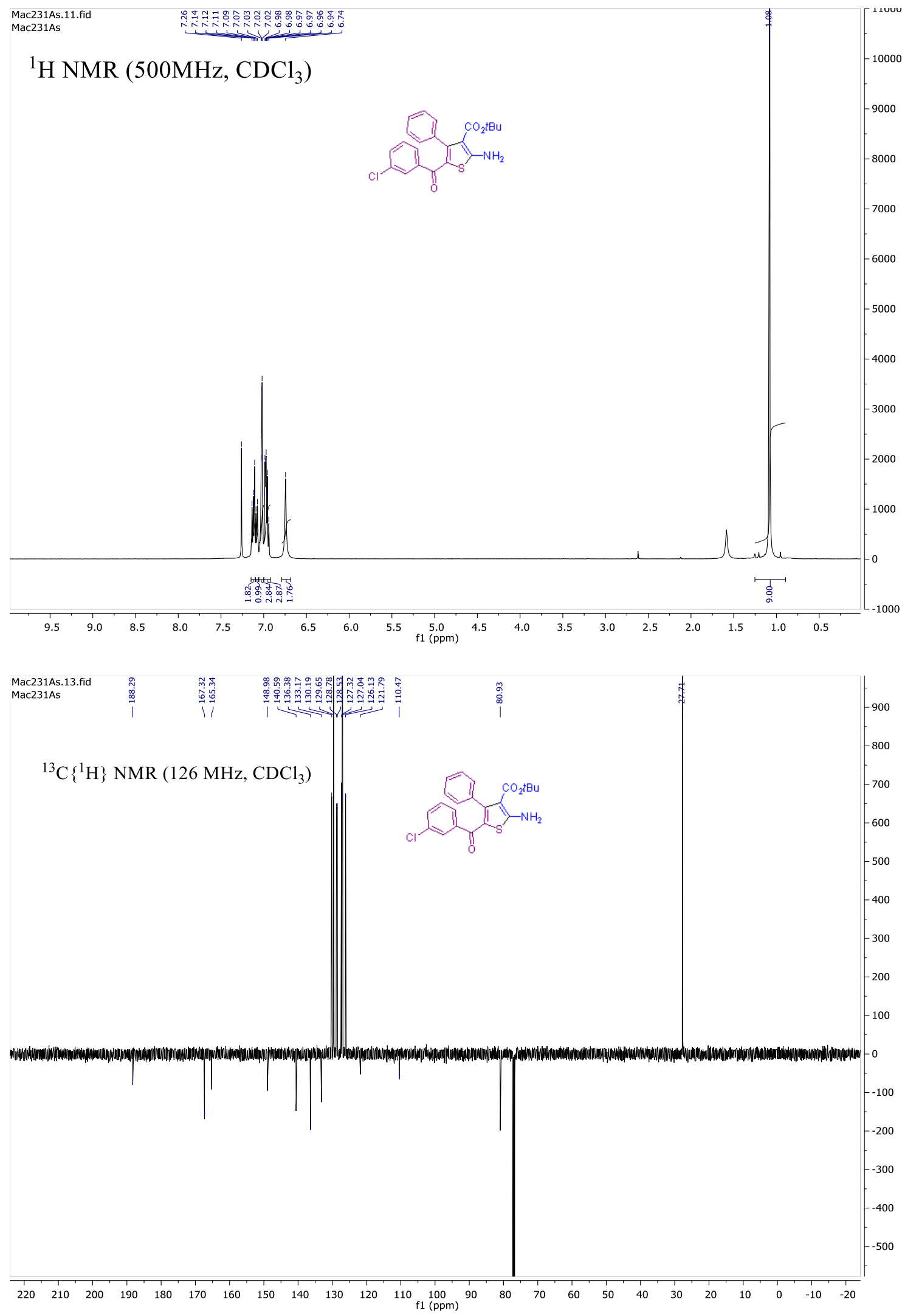
tert-Butyl 2-amino-5-benzoyl-4-(3-chlorophenyl)thiophene-3-carboxylate (3caa)




tert-Butyl 2-amino-5-(3-bromobenzoyl)-4-phenylthiophene-3-carboxylate (3ada)
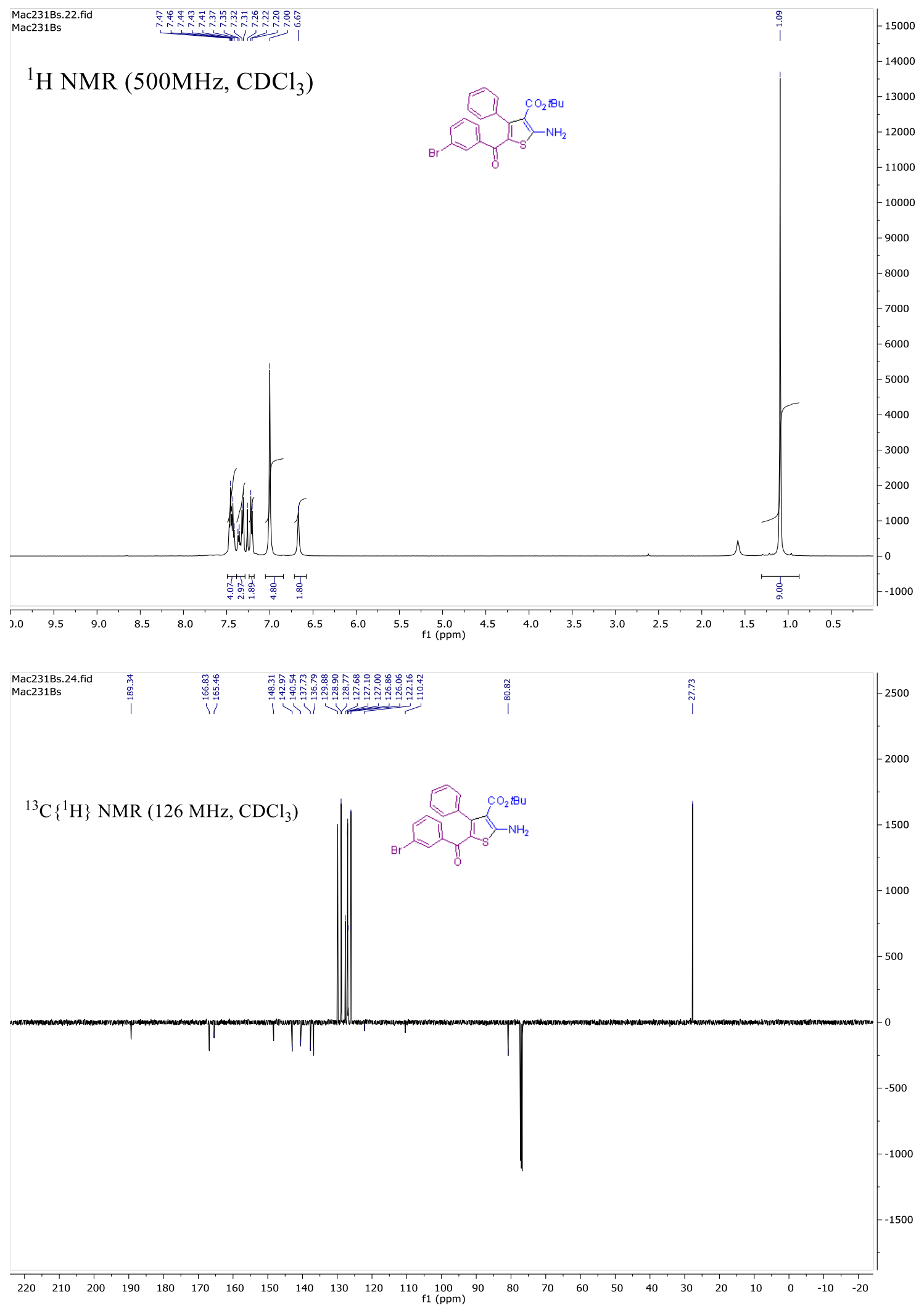
tert-Butyl 2-amino-5-benzoyl-4-(3-bromophenyl)thiophene-3-carboxylate (3daa)
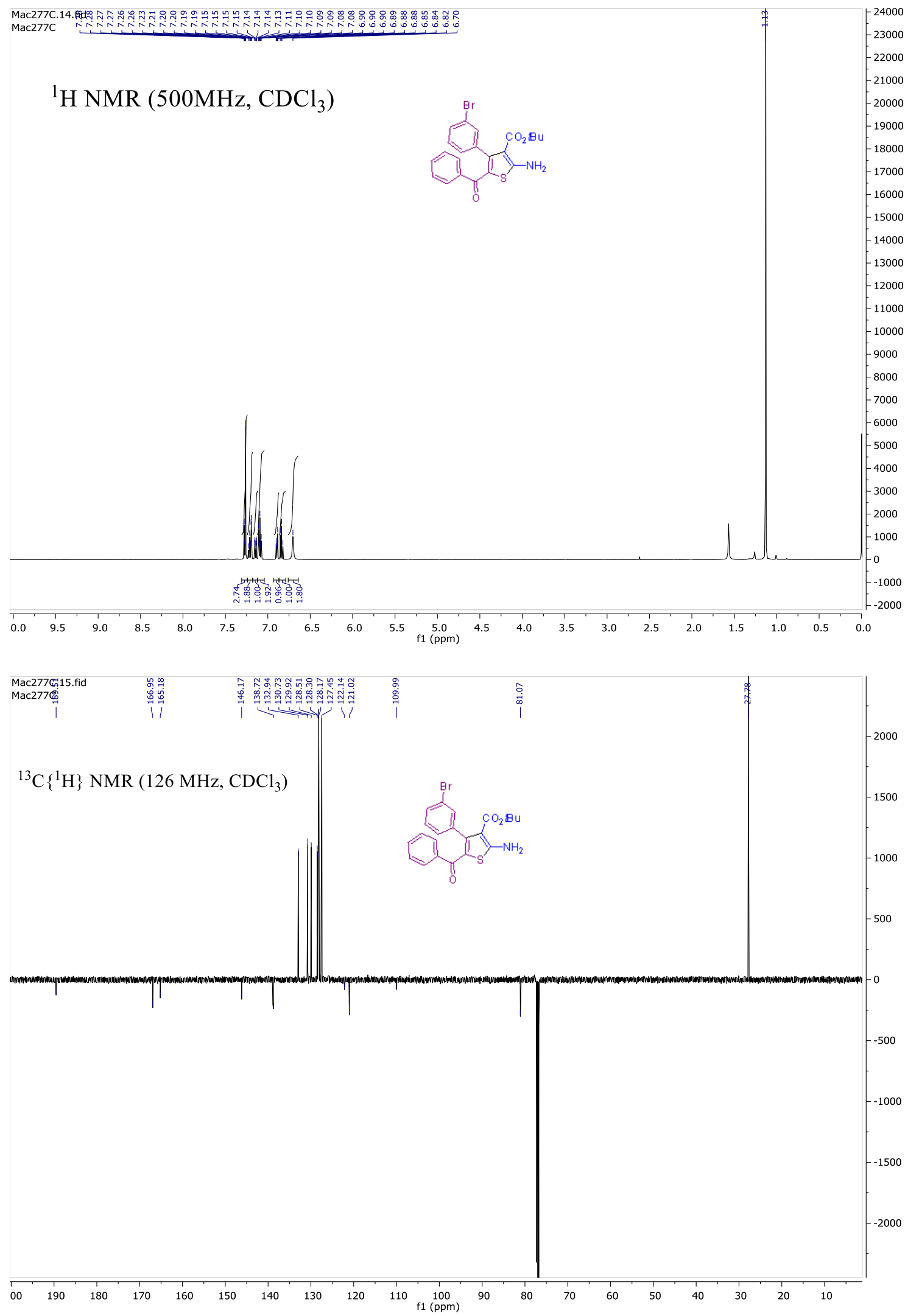
tert-Butyl 2-amino-5-(2-chlorobenzoyl)-4-phenylthiophene-3-carboxylate (3aea)
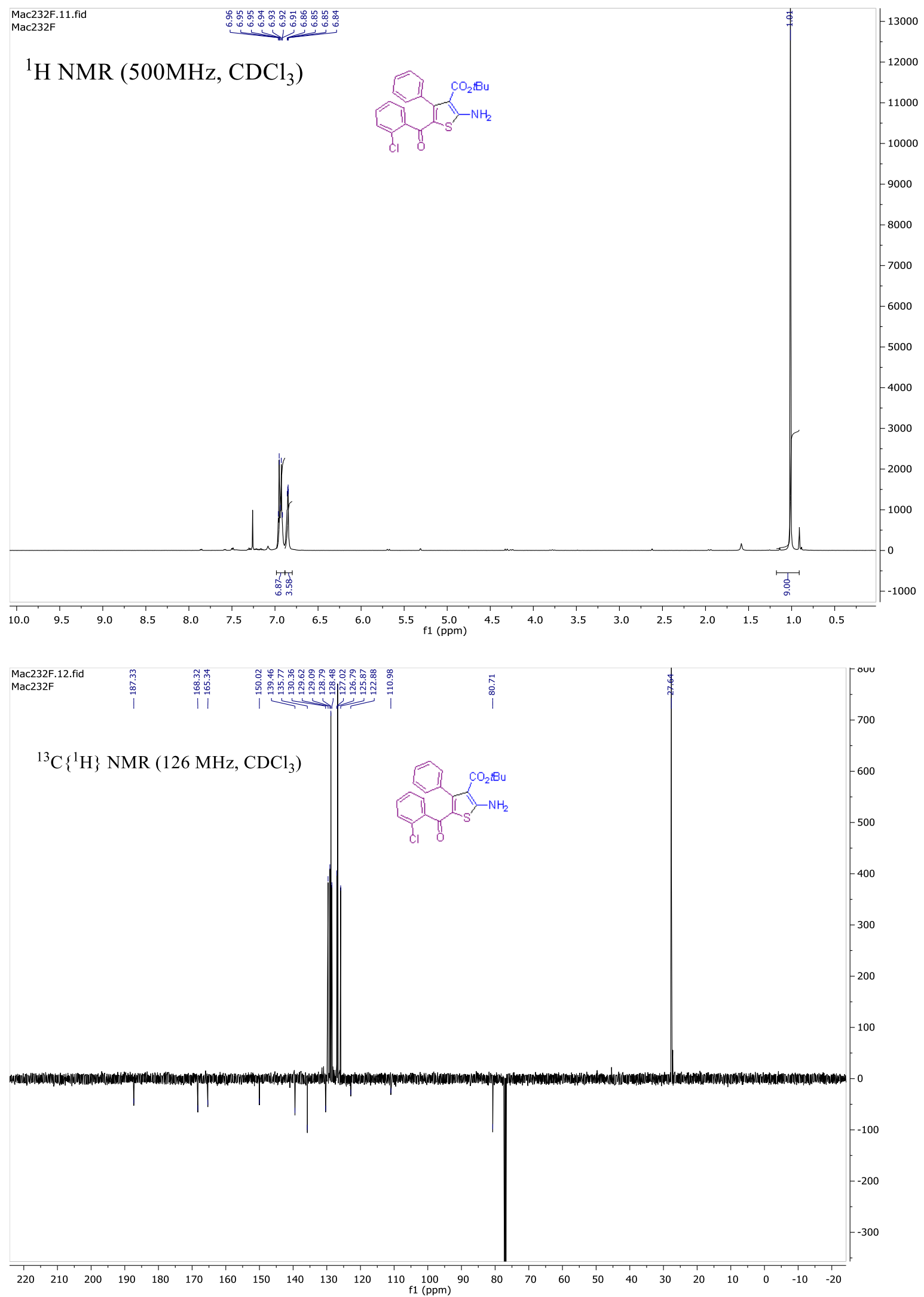
tert-Butyl 2-amino-5-benzoyl-4-(2-chlorophenyl)thiophene-3-carboxylate (3eaa)

tert-Butyl 2-amino-5-(2-bromobenzoyl)-4-phenylthiophene-3-carboxylate (3afa)
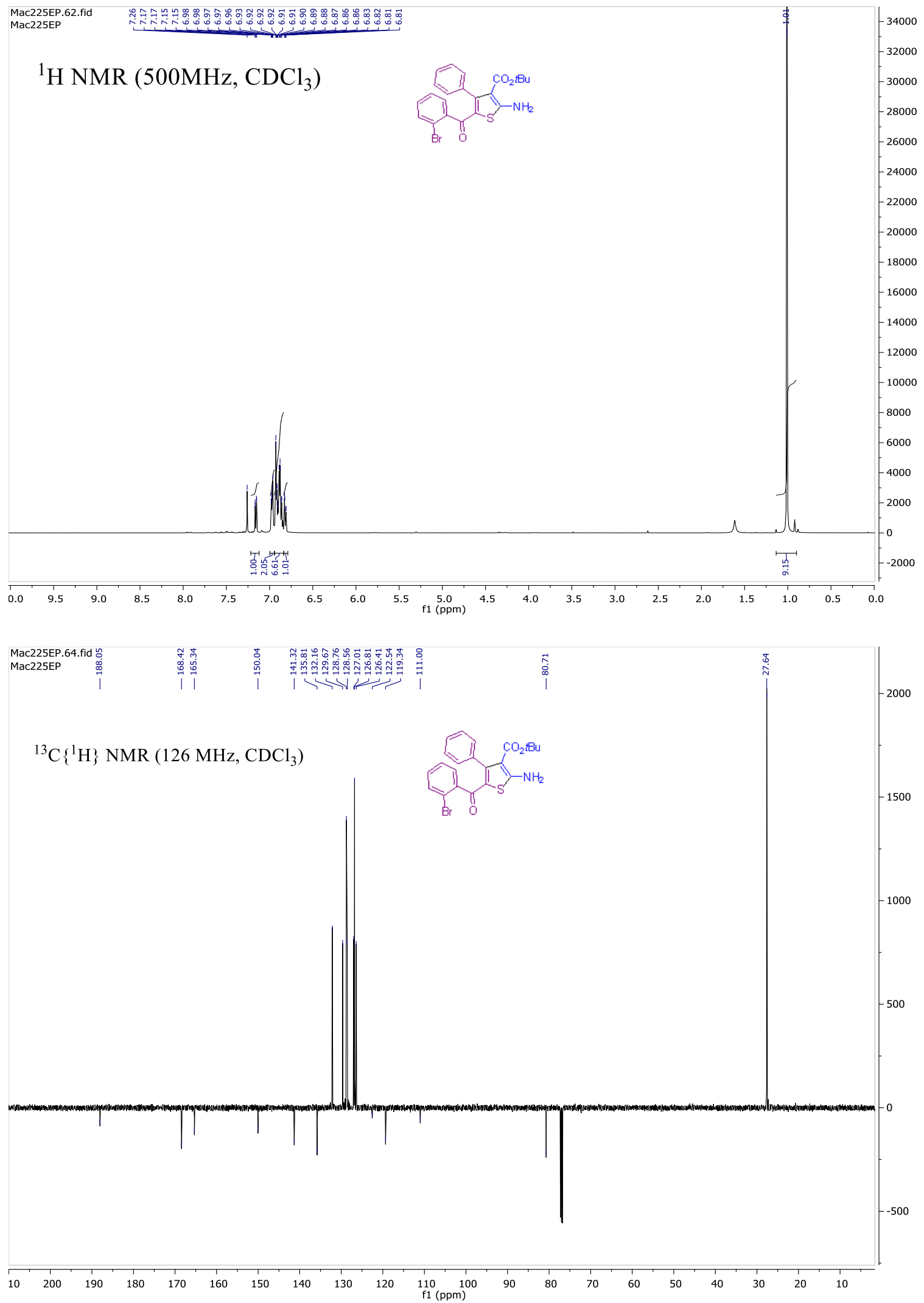
tert-Butyl 2-amino-5-benzoyl-4-(2-bromophenyl)thiophene-3-carboxylate (3faa)

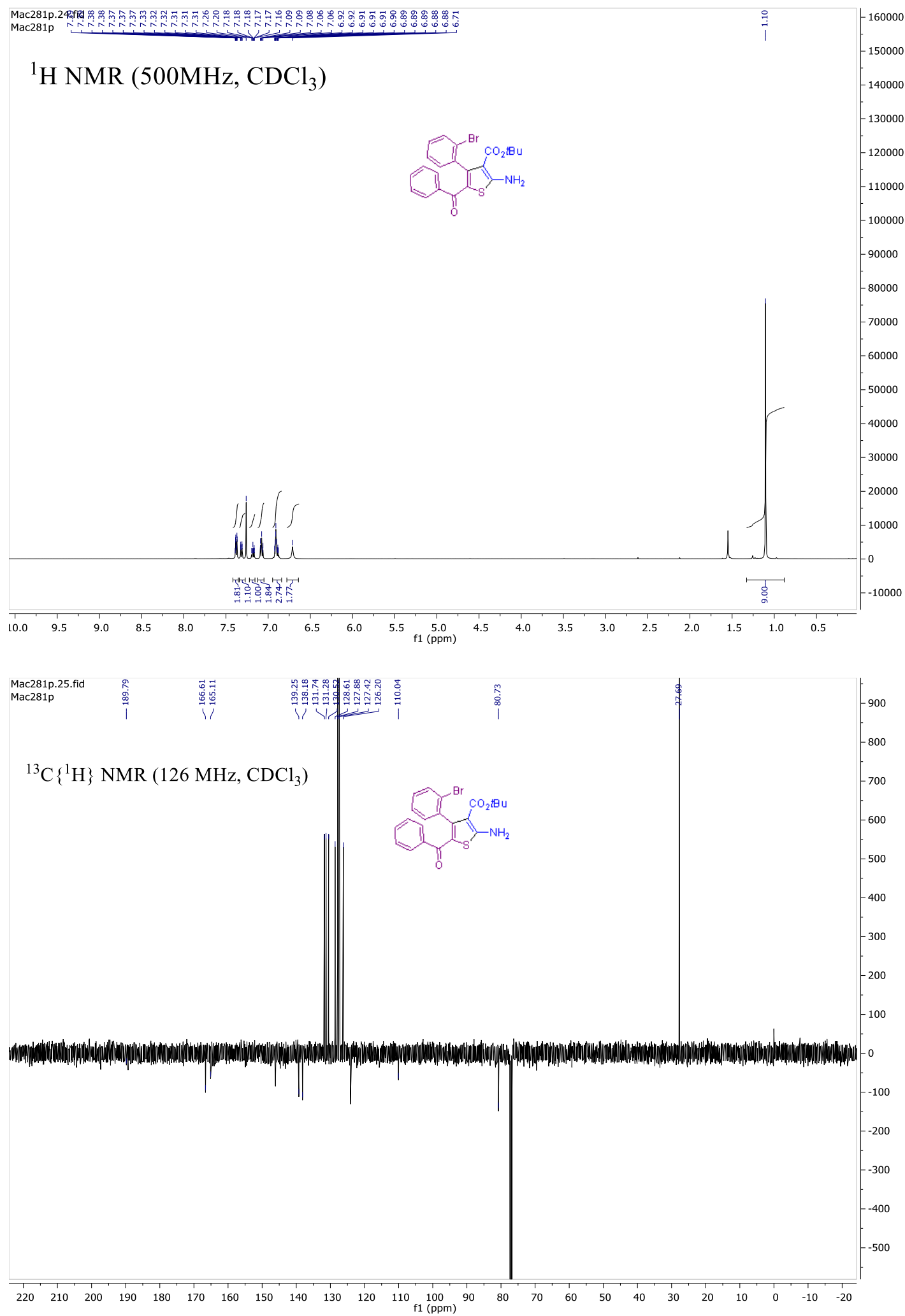


tert-Butyl 5-(2-naphthoyl)-2-amino-4-phenylthiophene-3-carboxylate (3aga)

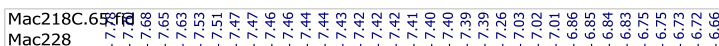

${ }^{1} \mathrm{H}$ NMR $\left(500 \mathrm{MHz}, \mathrm{CDCl}_{3}\right)$

tert-Butyl 2-amino-5-benzoyl-4-(naphthalen-2-yl)thiophene-3-carboxylate (3gaa)
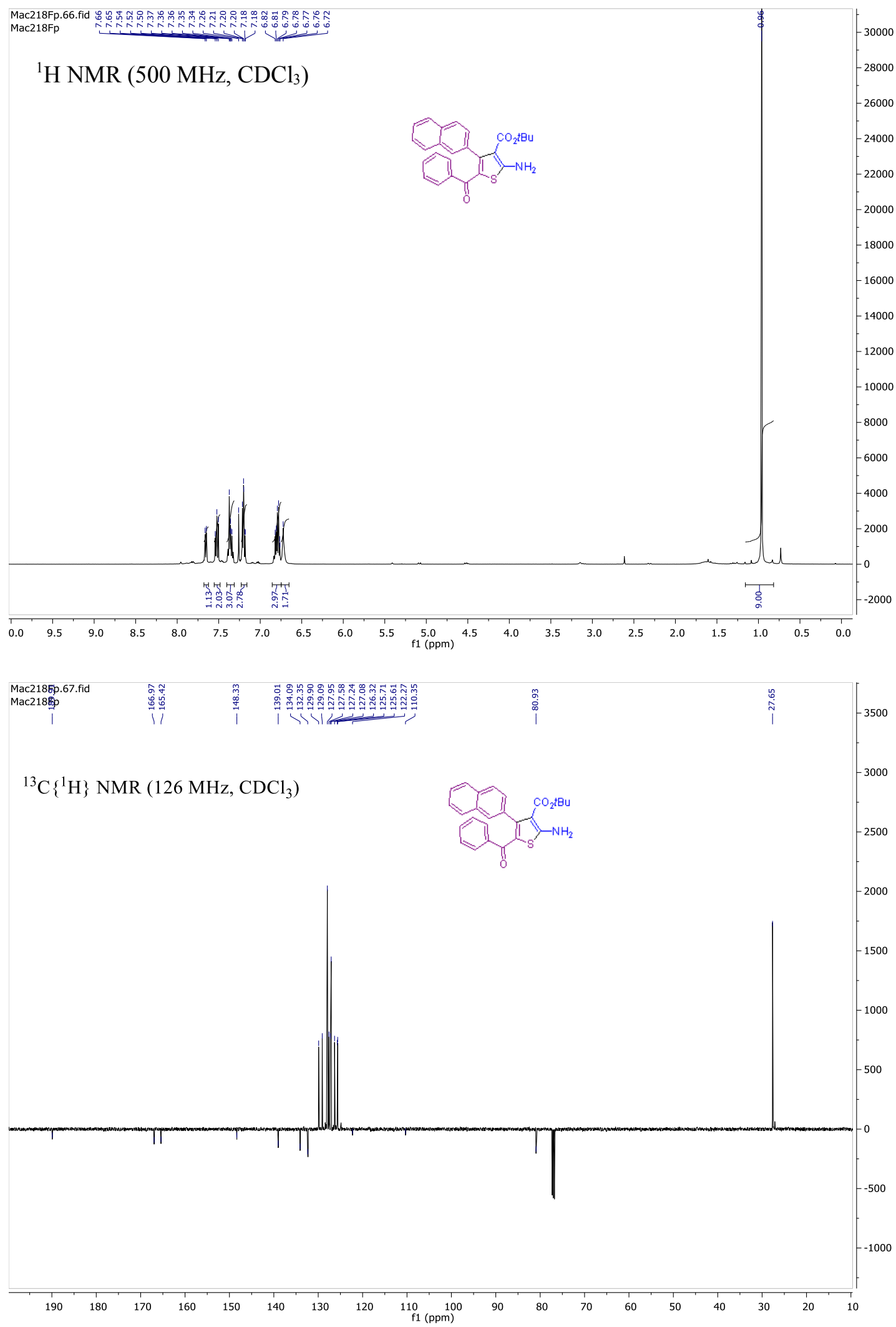
tert-Butyl 2-amino-5-benzoyl-4-(p-tolyl)thiophene-3-carboxylate (3haa)

tert-Butyl 2-amino-5-benzoyl-4-(4-isopropylphenyl)thiophene-3-carboxylate (3iaa)
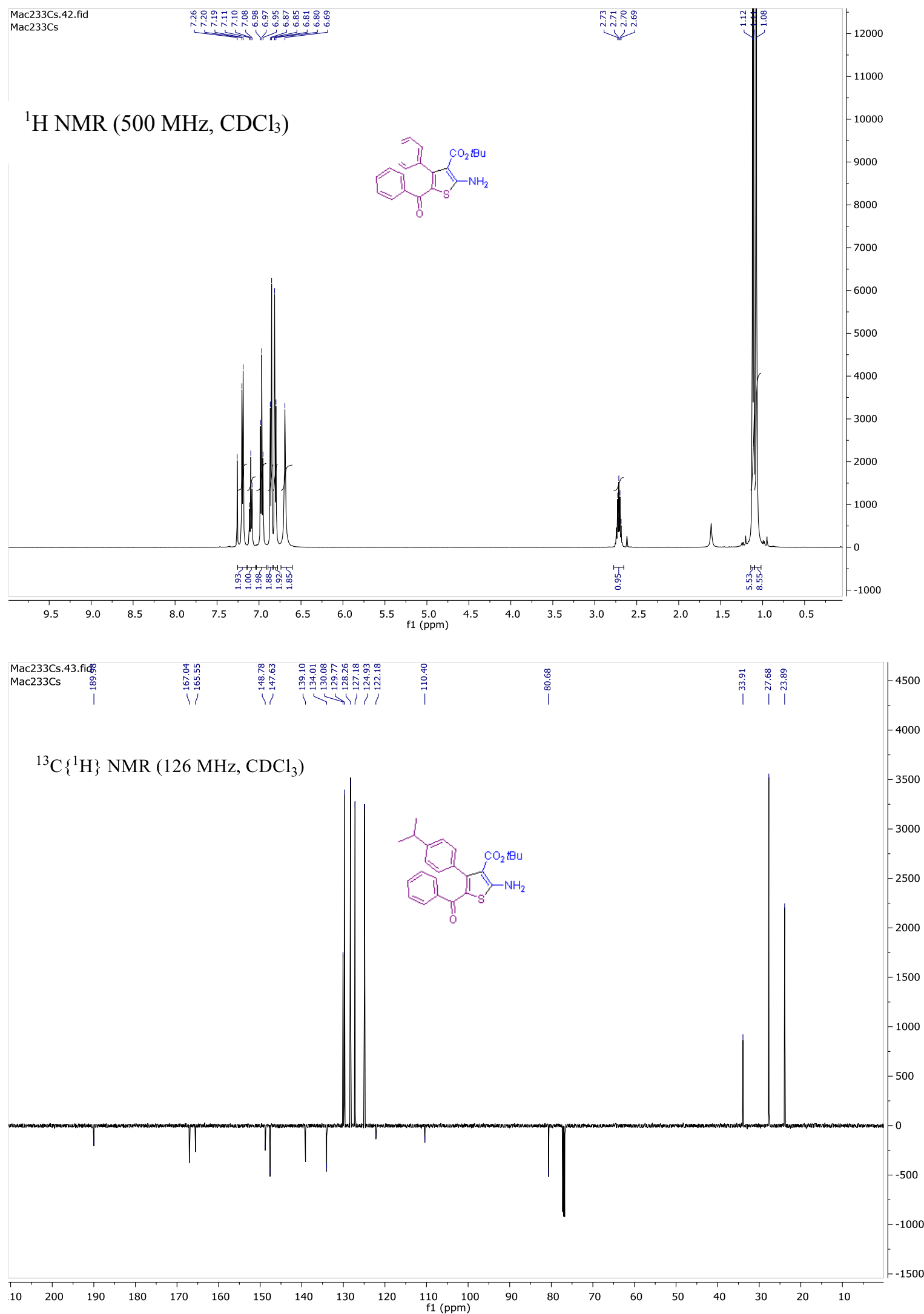
tert-Butyl 2-amino-5-benzoyl-4-(o-tolyl)thiophene-3-carboxylate (3jaa)
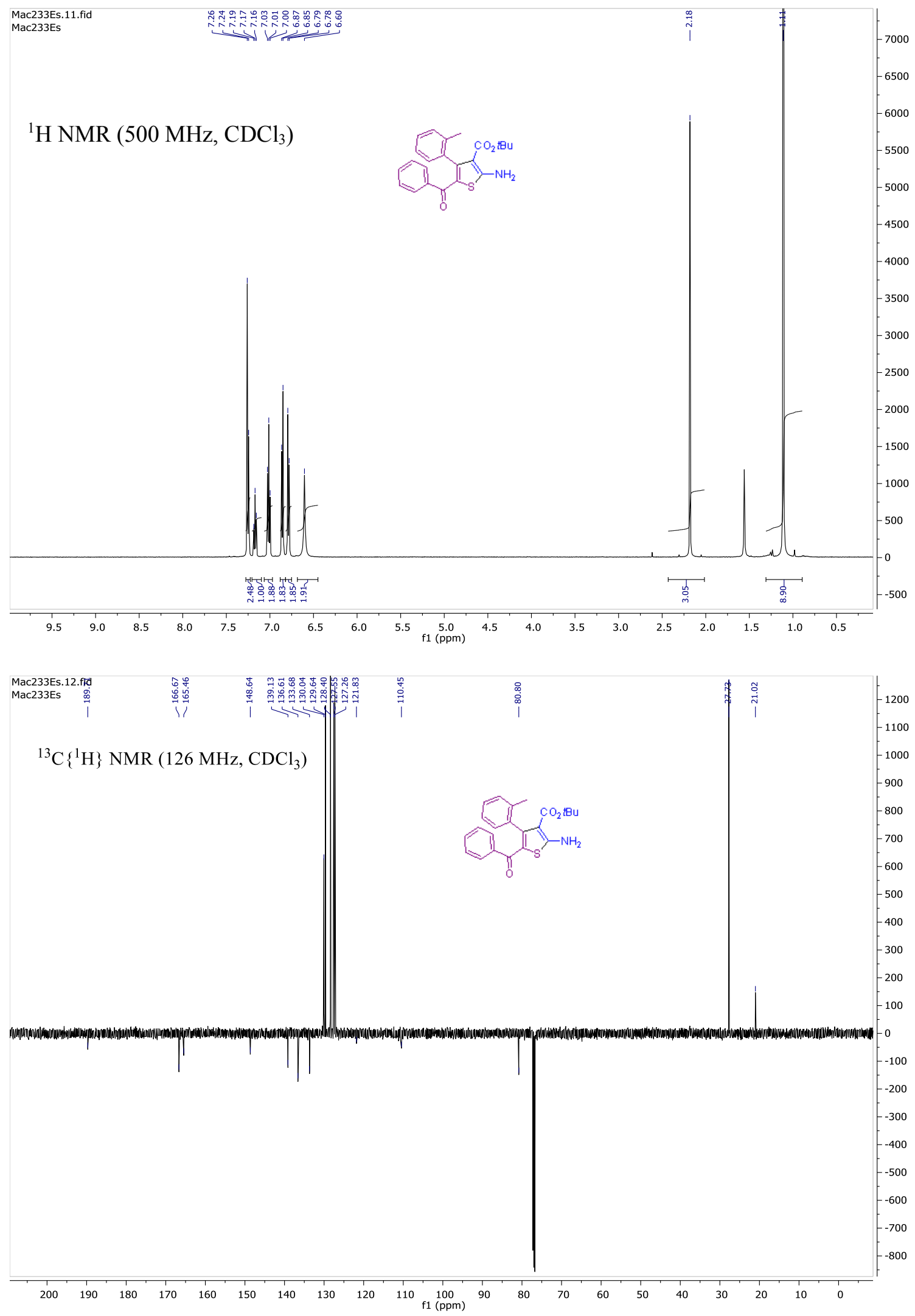
tert-Butyl 2-amino-5-benzoyl-4-(4-chlorophenyl)thiophene-3-carboxylate (3kaa)
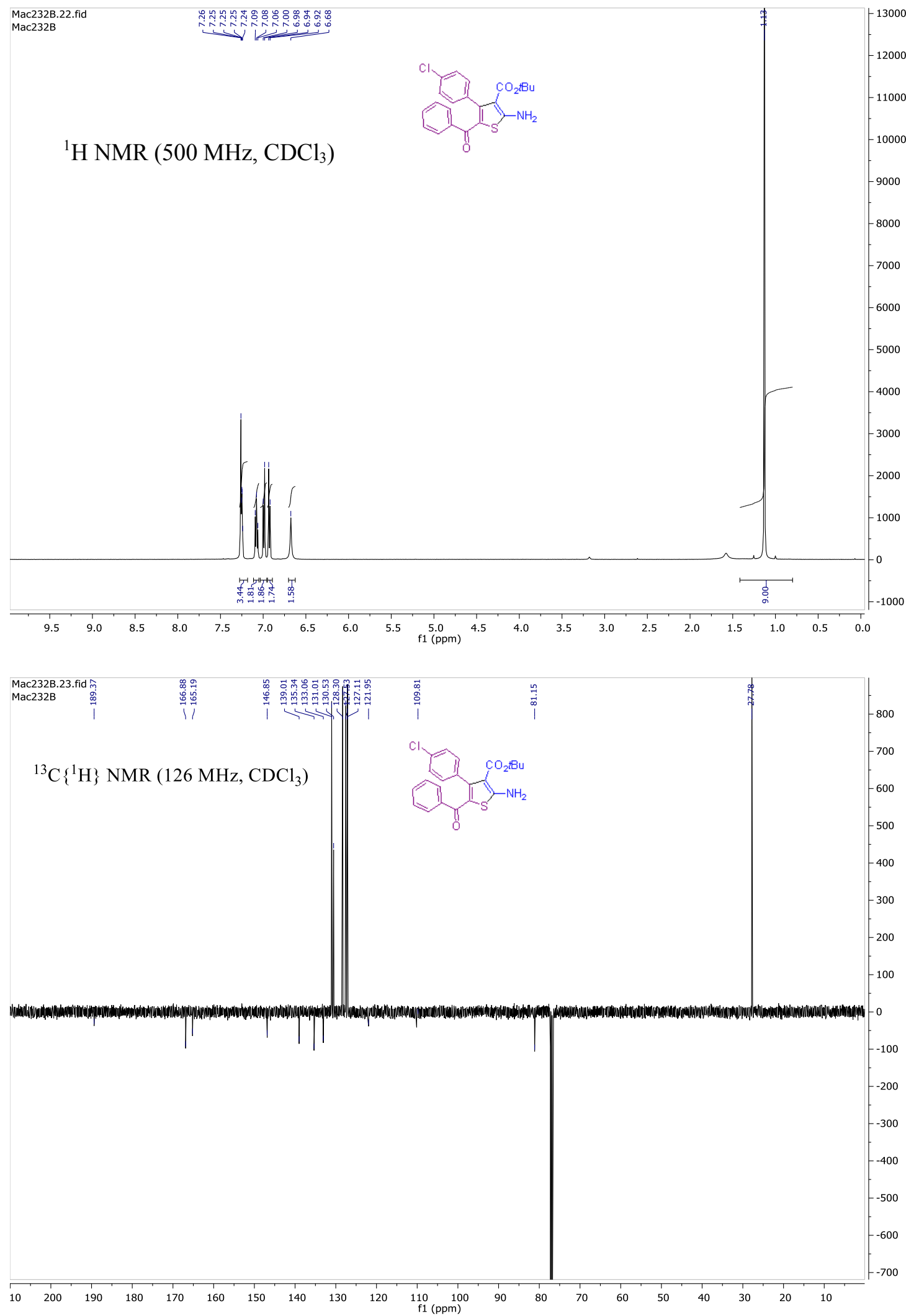
tert-Butyl 2-amino-5-benzoyl-4-(2,4dichlorophenyl)thiophene-3-carboxylate (3laa)

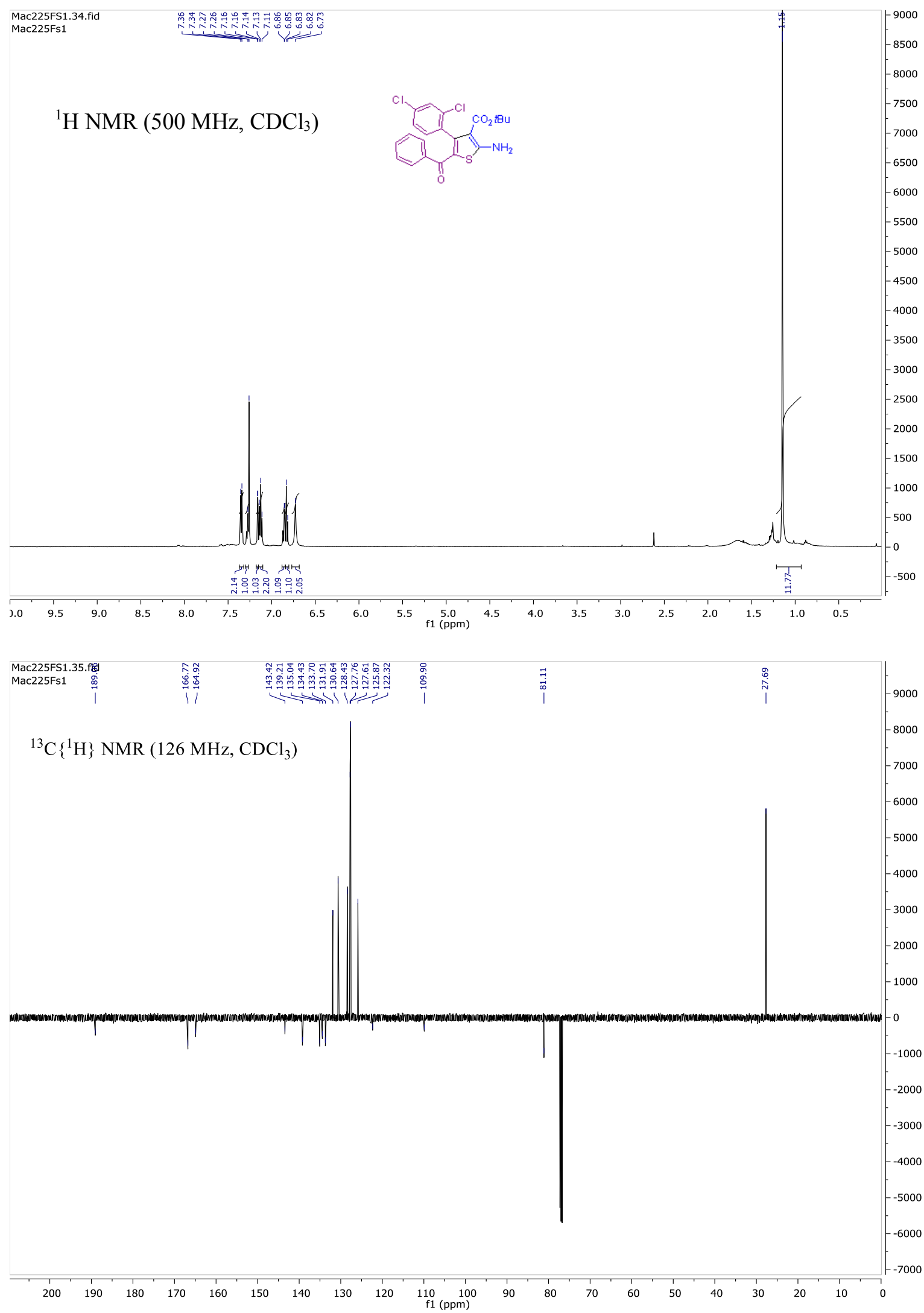


tert-Butyl 2-amino-5-benzoyl-4-(4-bromophenyl)thiophene-3-carboxylate (3maa)
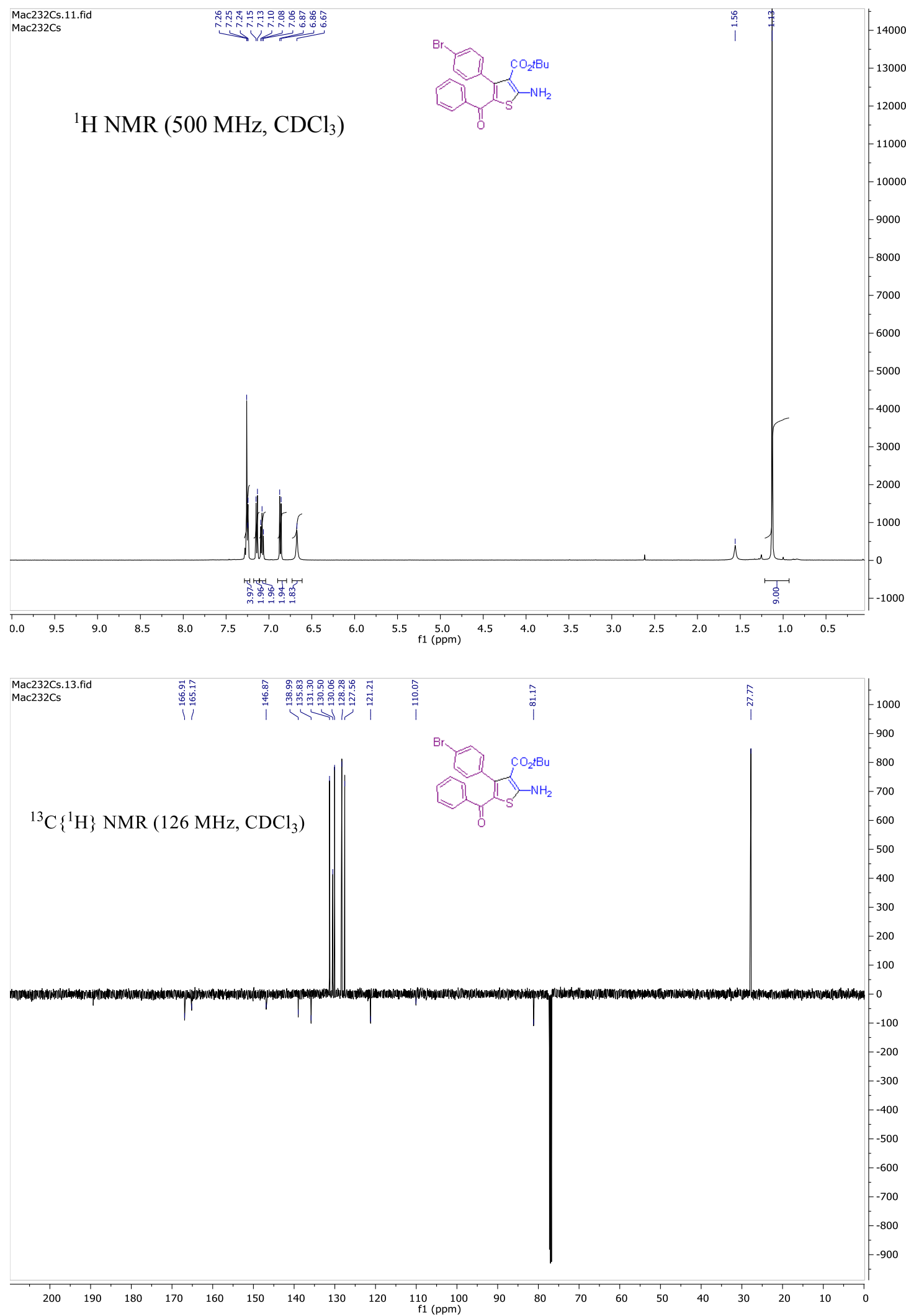
tert-Butyl 2-amino-5-benzoyl-4-(4-methoxyphenyl)thiophene-3-carboxylate (3naa)

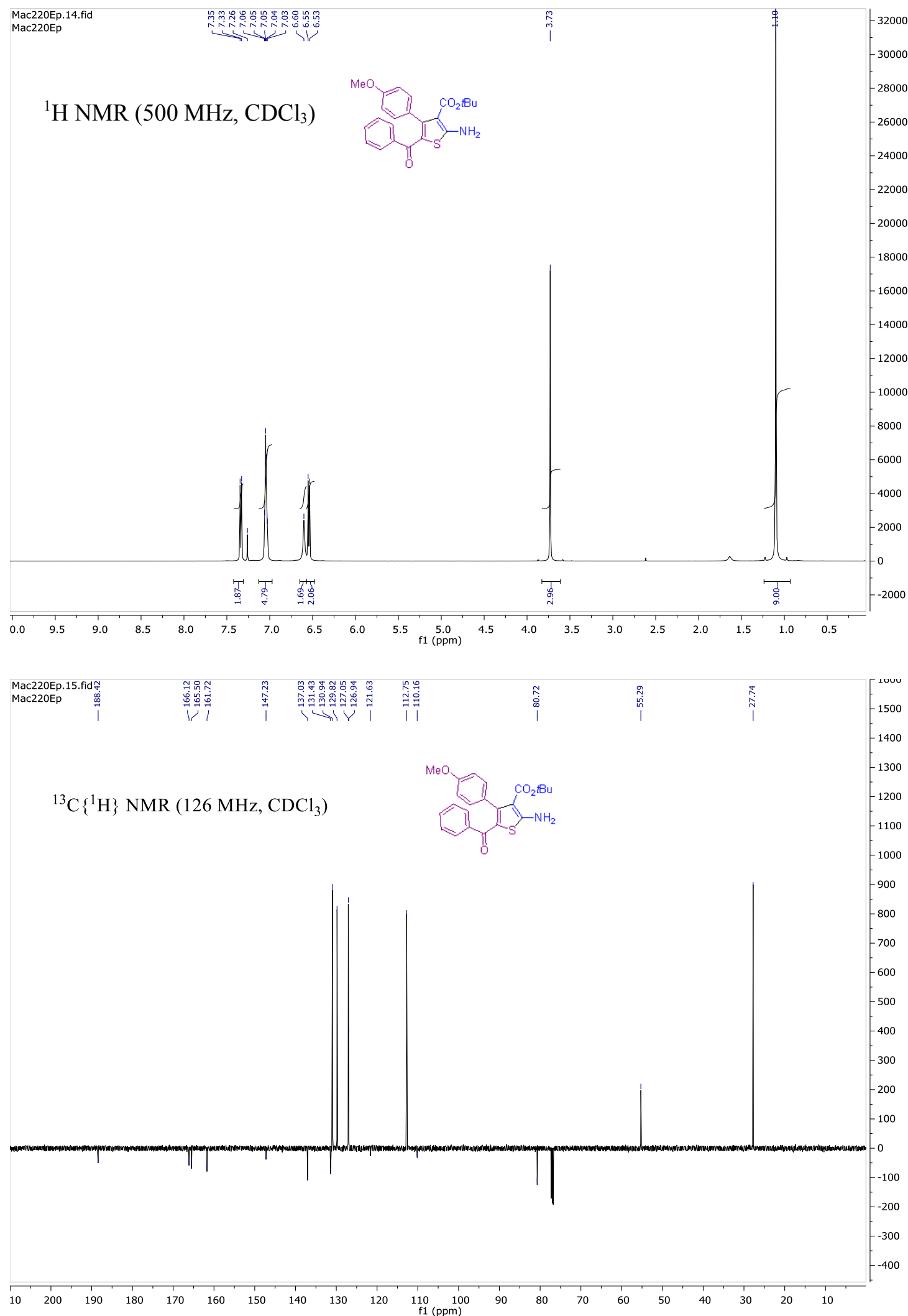


tert-Butyl 2-amino-5-benzoyl-4-(3-methoxyphenyl)thiophene-3-carboxylate (3oaa)
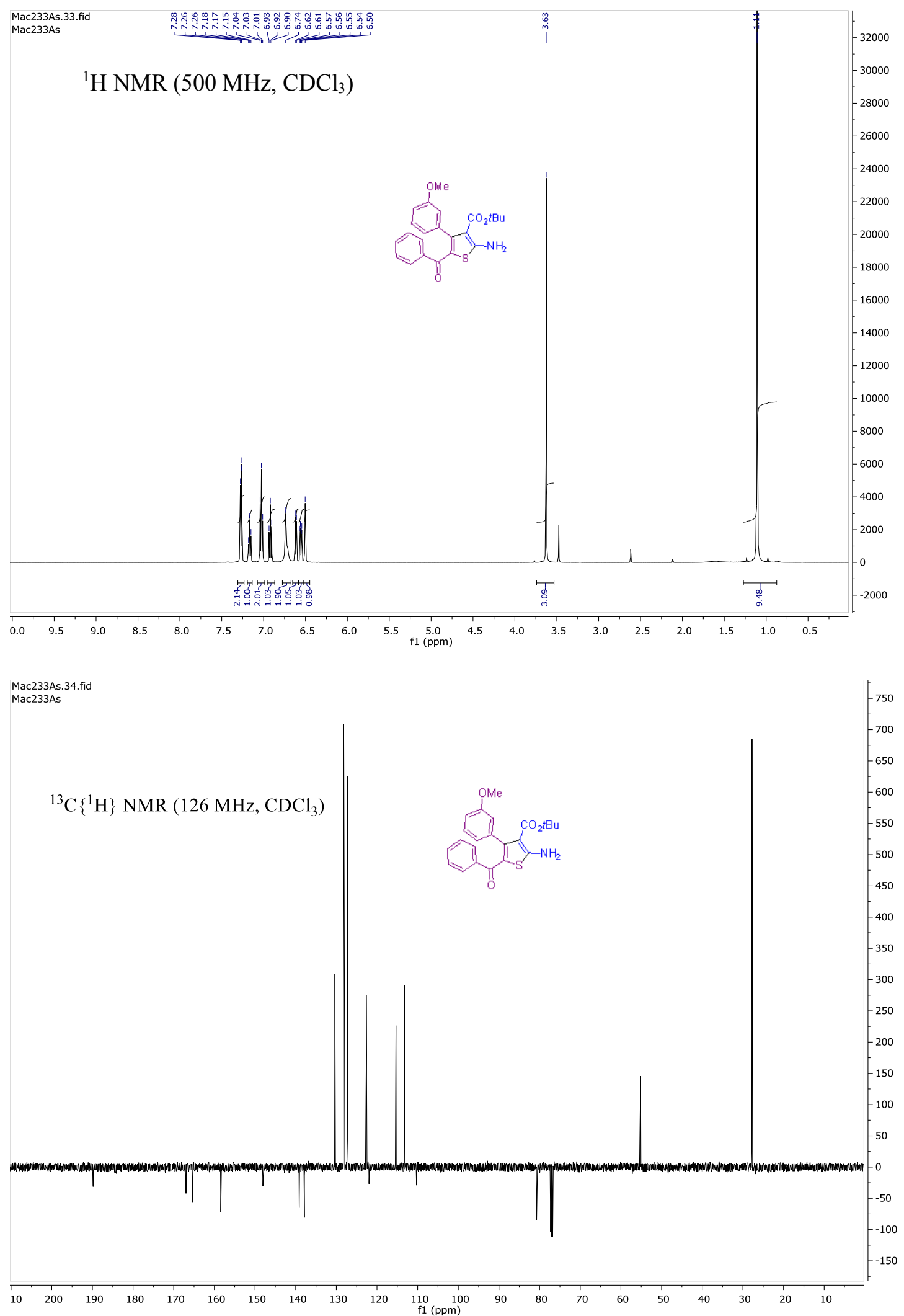
tert-Butyl 2-amino-5-benzoyl-4-(4-(ethoxycarbonyl)phenyl)thiophene-3-carboxylate (3paa)
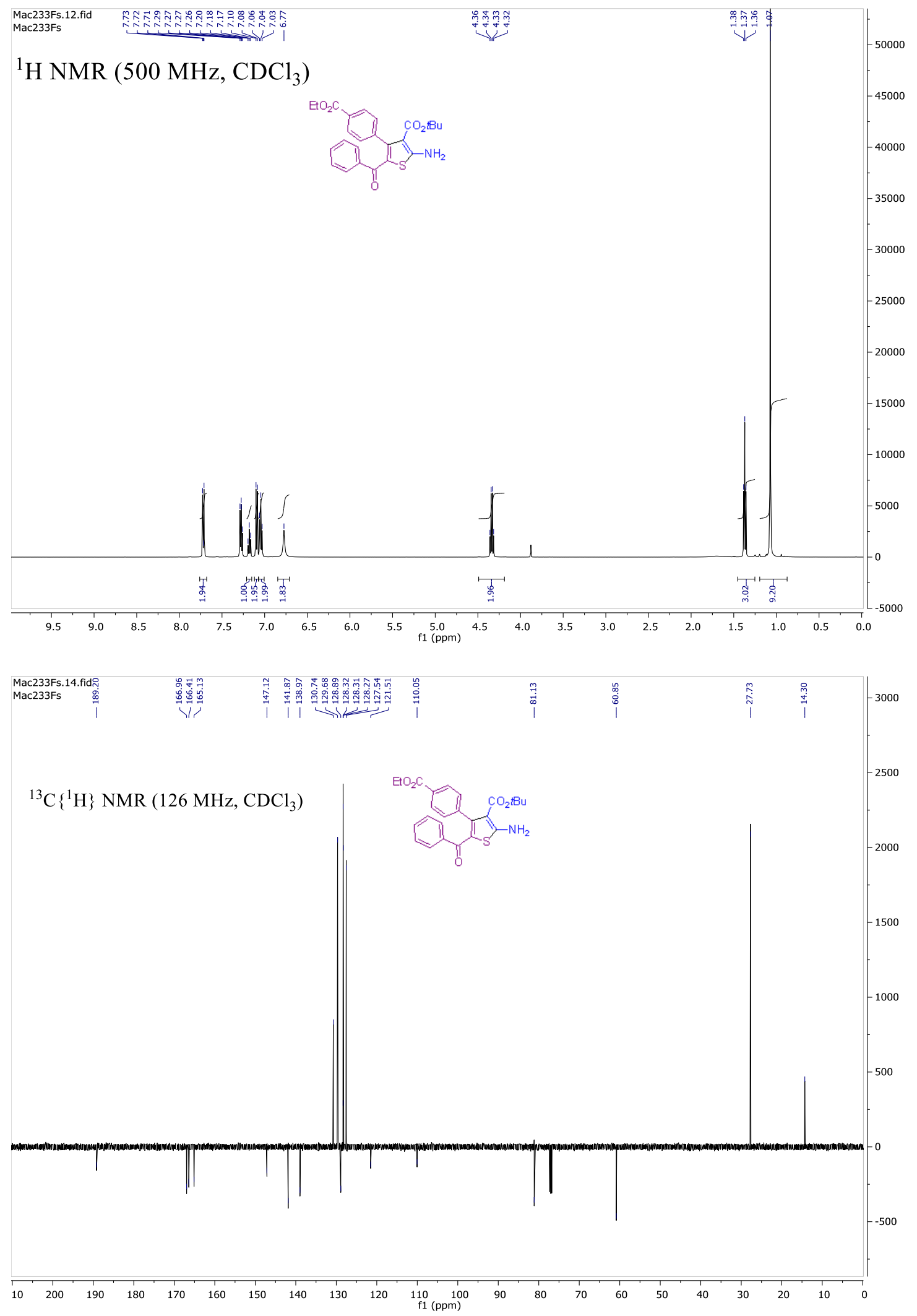
tert-Butyl 2-amino-5-benzoyl-4-(4-cyanophenyl)thiophene-3-carboxylate (3qaa)

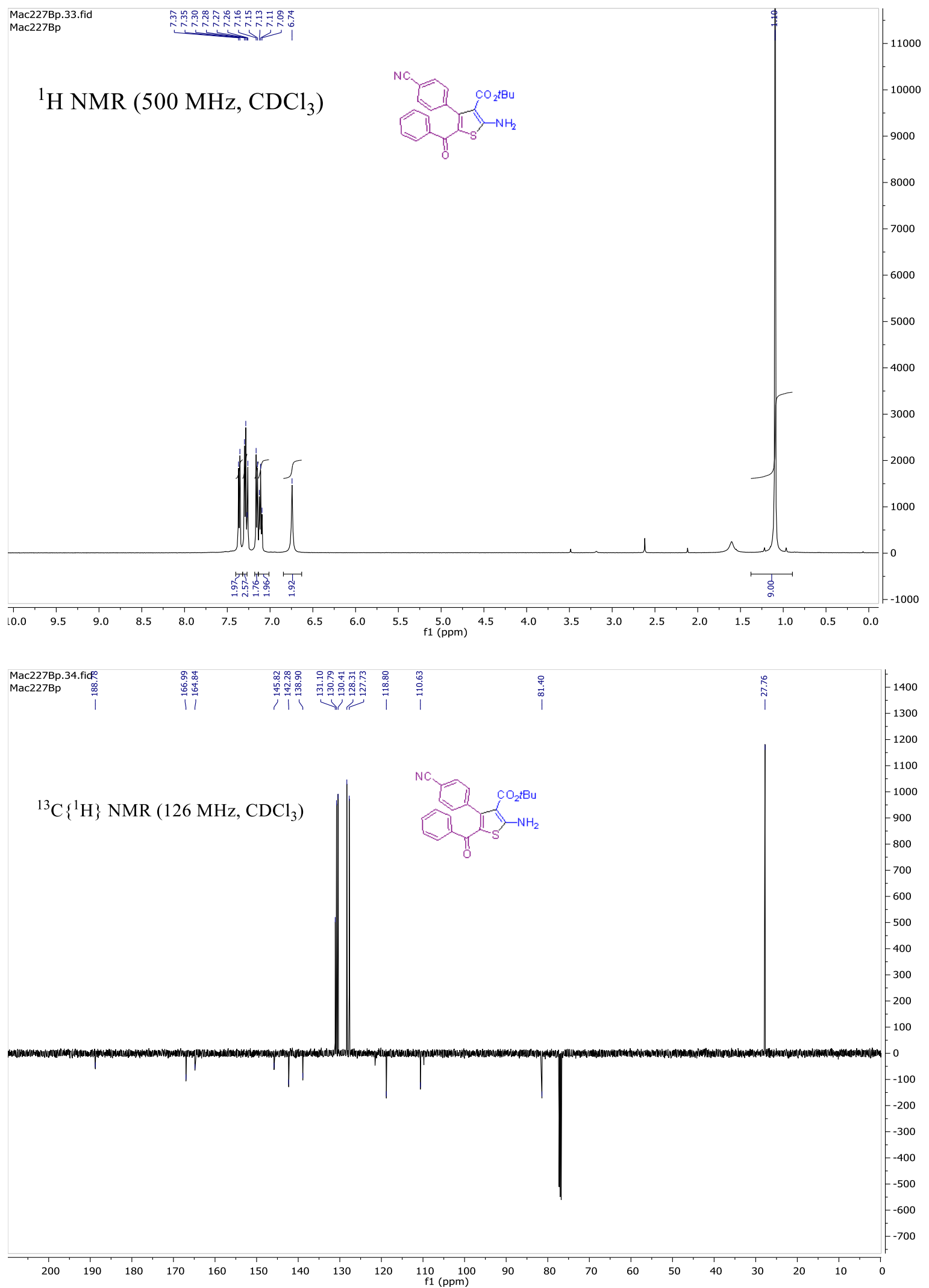


tert-Butyl 2-amino-5-benzoyl-4-(pyridin-2-yl)thiophene-3-carboxylate (3raa)
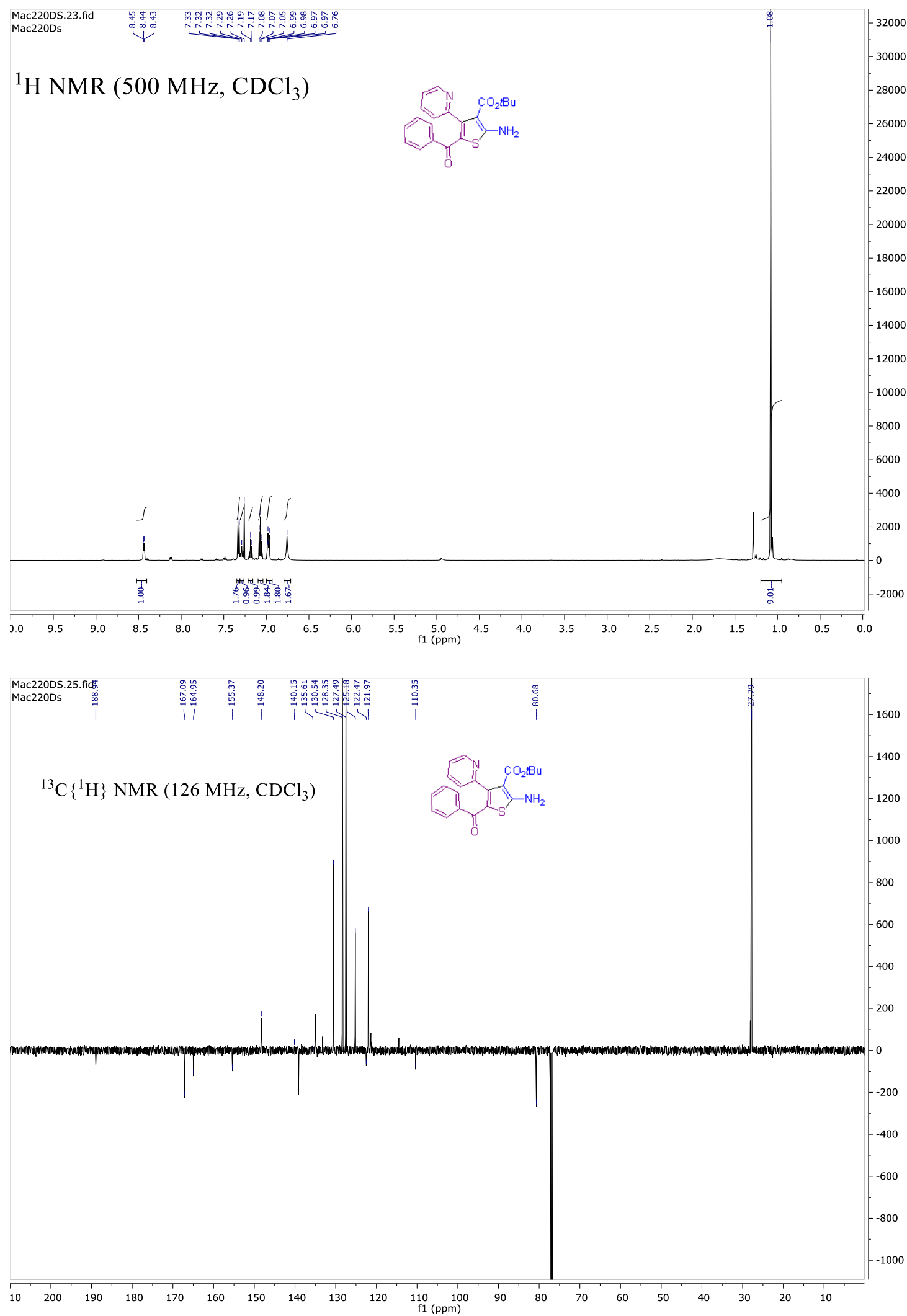
tert-Butyl 5-([1,1'-biphenyl]-4-carbonyl)-2-amino-4-phenylthiophene-3-carboxylate (3asa)
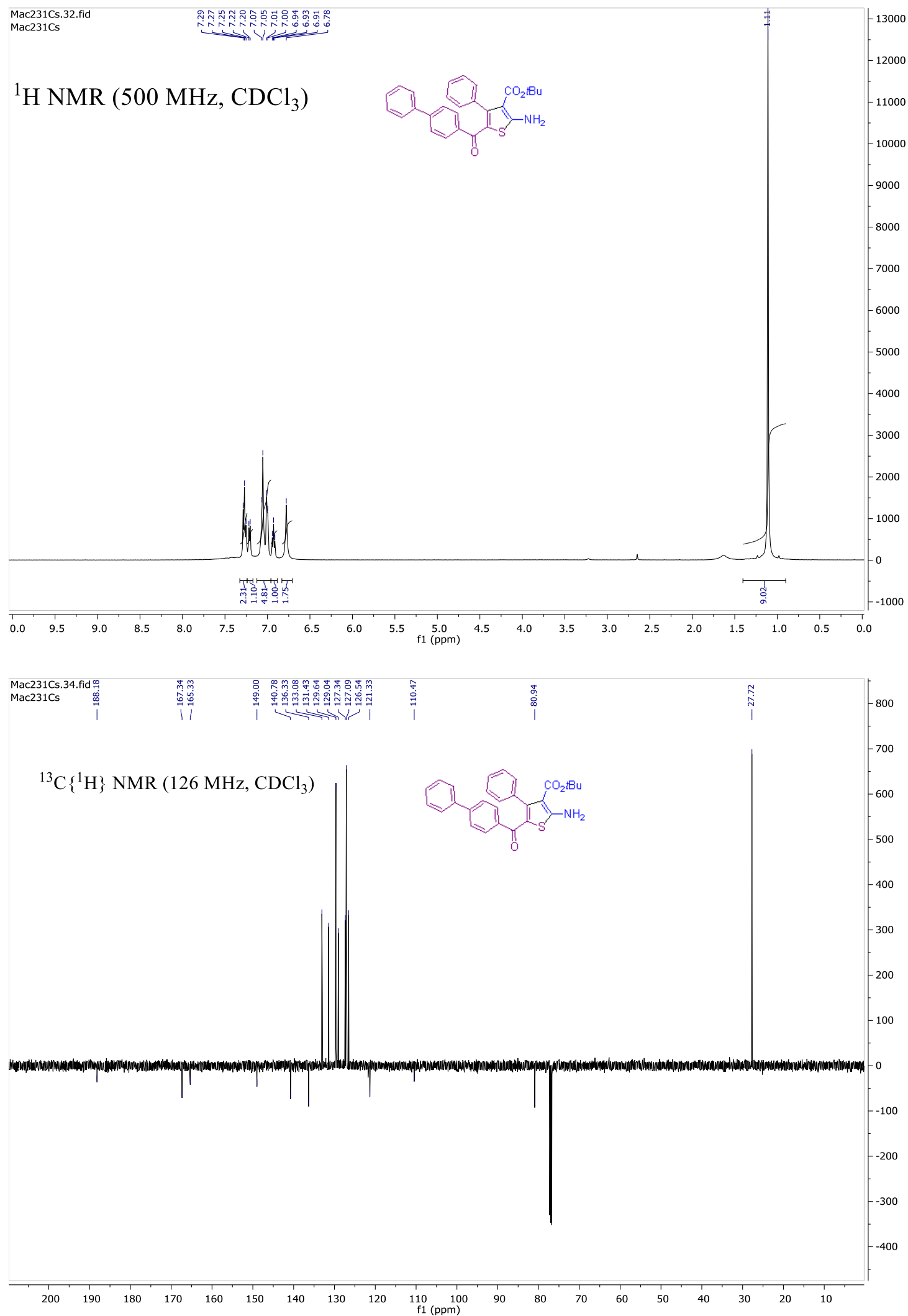
tert-Butyl 2-amino-5-(3-nitrobenzoyl)-4-phenylthiophene-3-carboxylate (3ata)
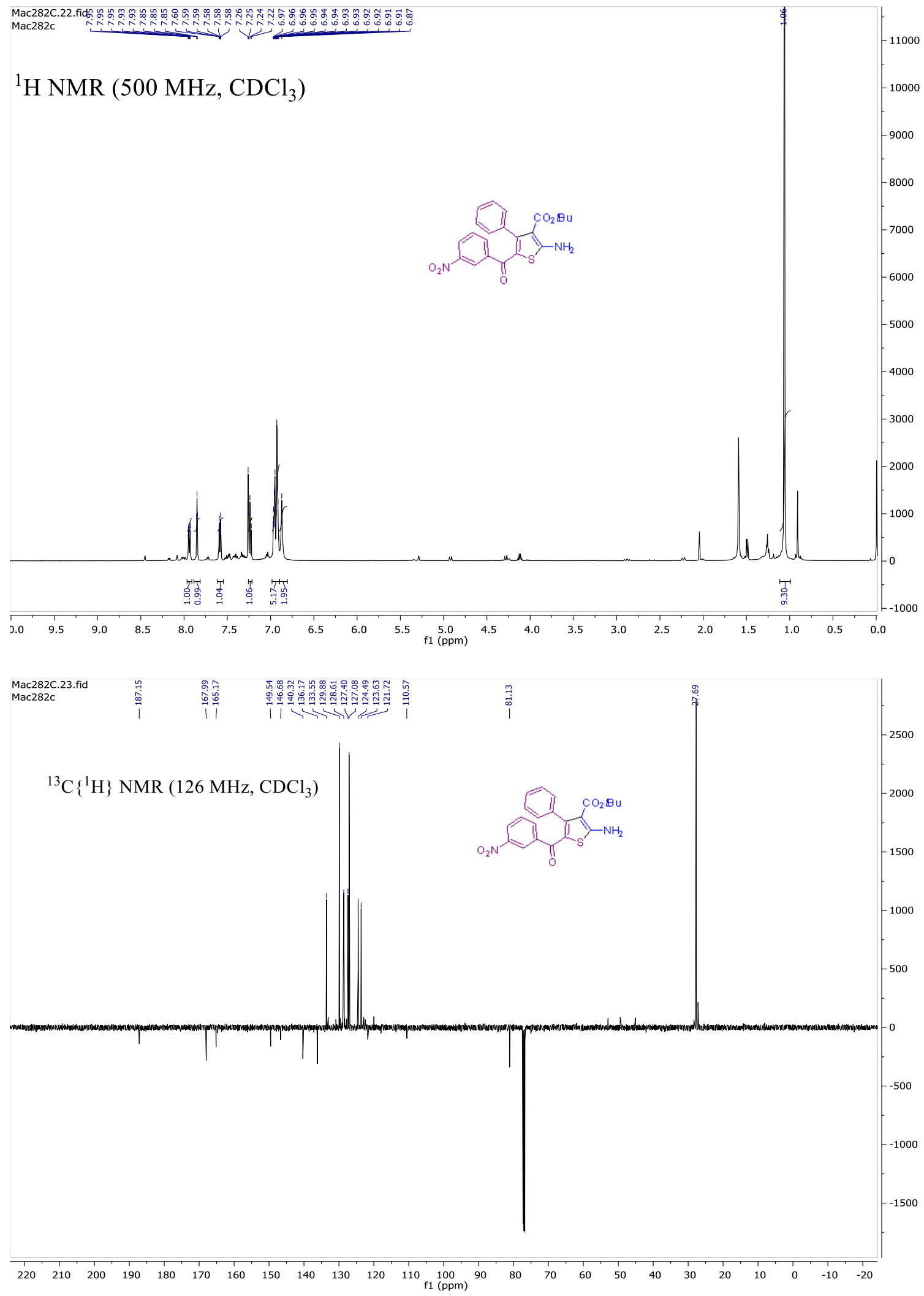
tert-Butyl 2-amino-4-(3-bromophenyl)-5-(4-methoxybenzoyl)thiophene-3-carboxylate (3dna)
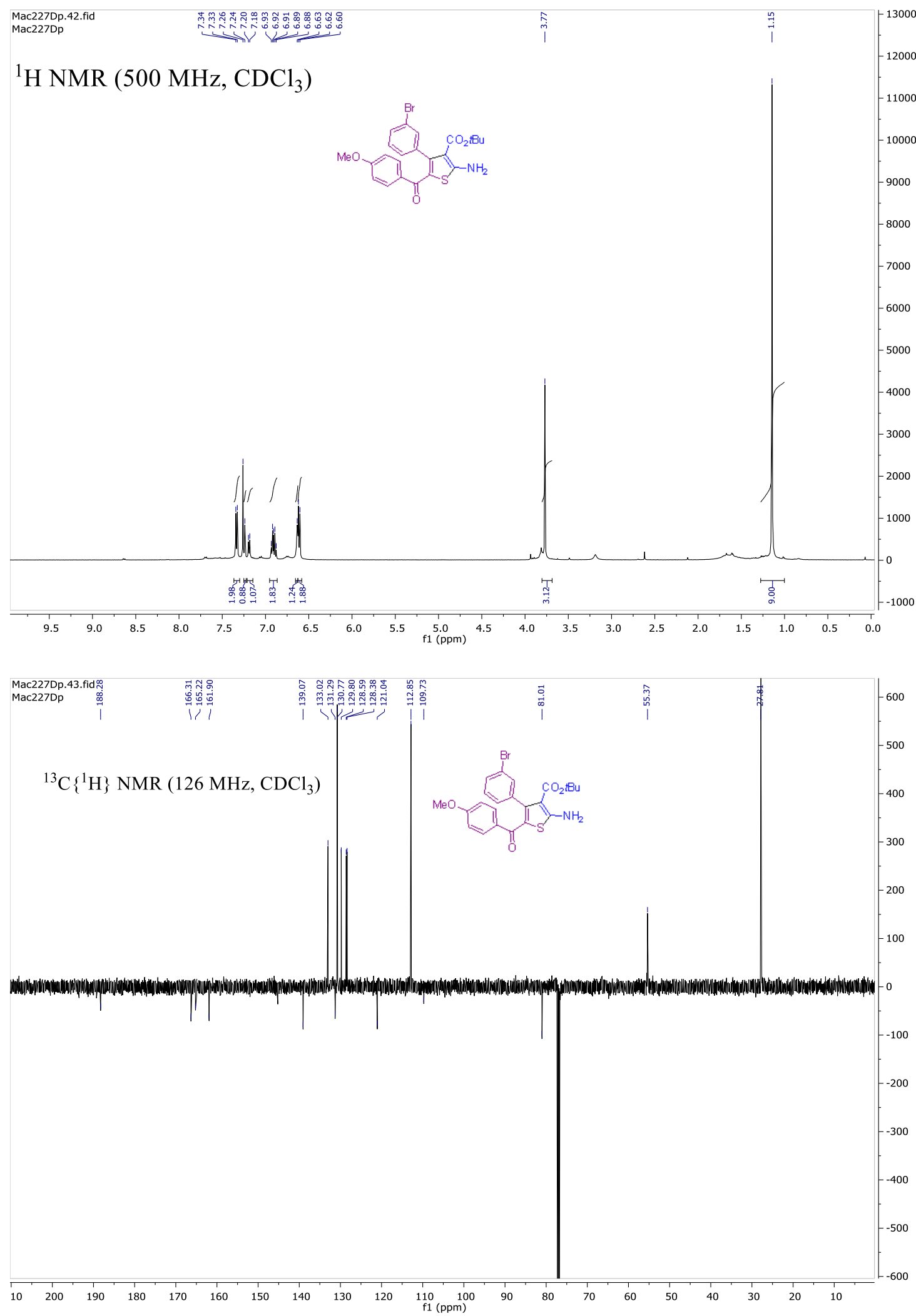
tert-Butyl 2-amino-5-(4-methoxybenzoyl)-4-(3-methoxyphenyl)thiophene-3-carboxylate (3ona)
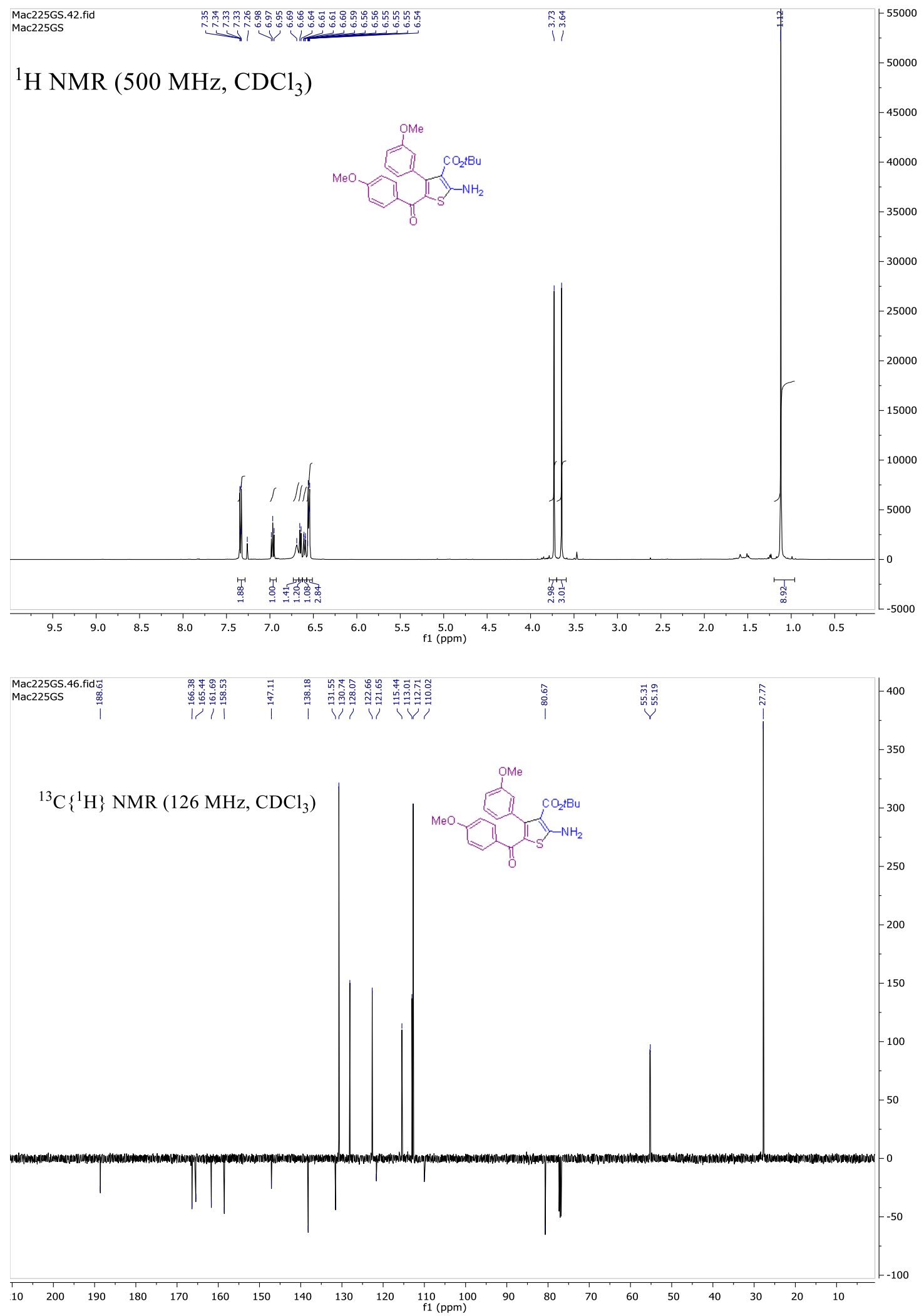
tert-Butyl 2-amino-5-(4-methoxybenzoyl)-4-(4-methoxyphenyl)thiophene-3-carboxylate (3nna)
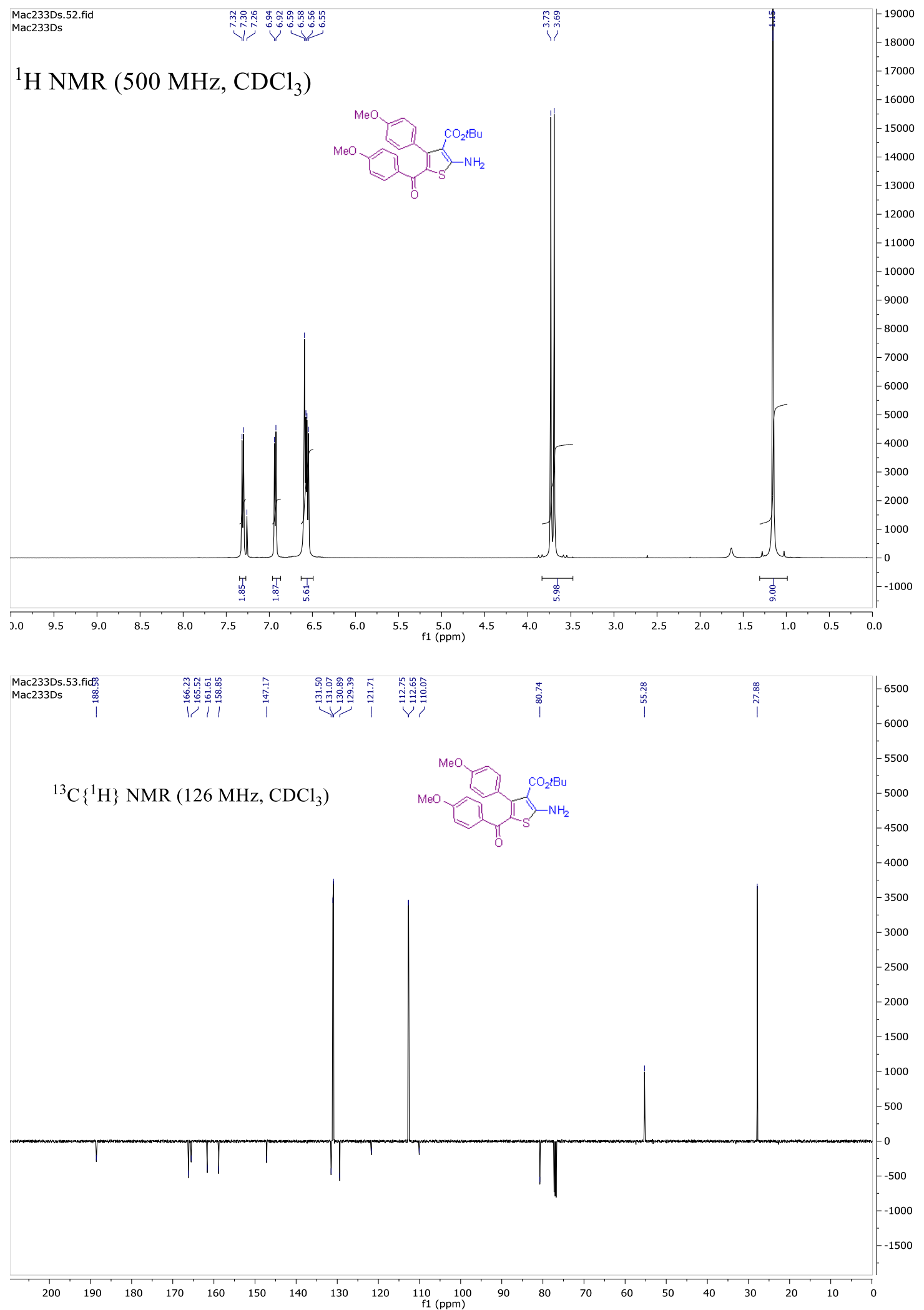
tert-Butyl 5-(2-naphthoyl)-2-amino-4-(furan-2-yl)thiophene-3-carboxylate (3uga)

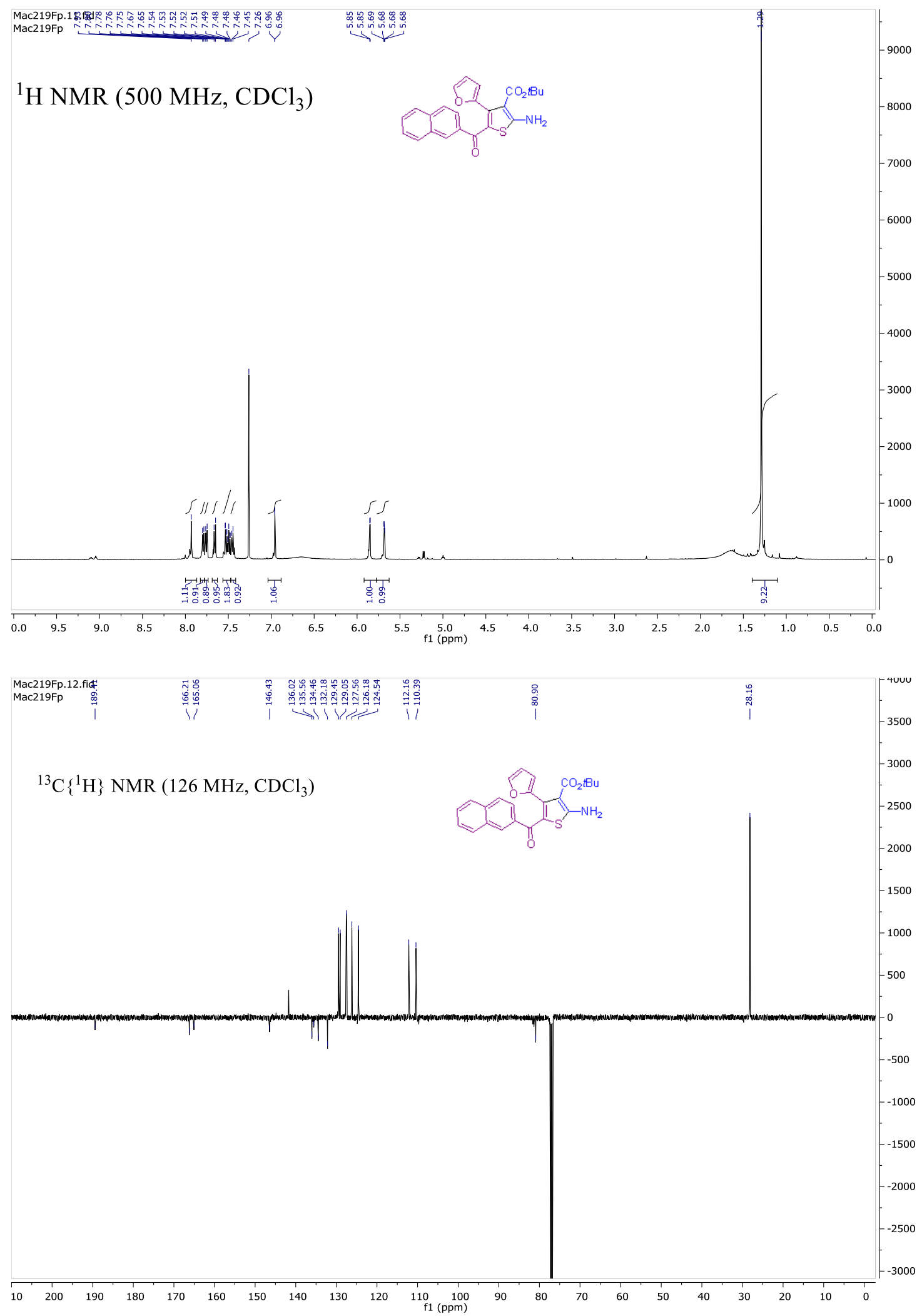


tert-Butyl 2-amino-4-(naphthalen-2-yl)-5-(thiophene-2-carbonyl)thiophene-3-carboxylate (3gva)
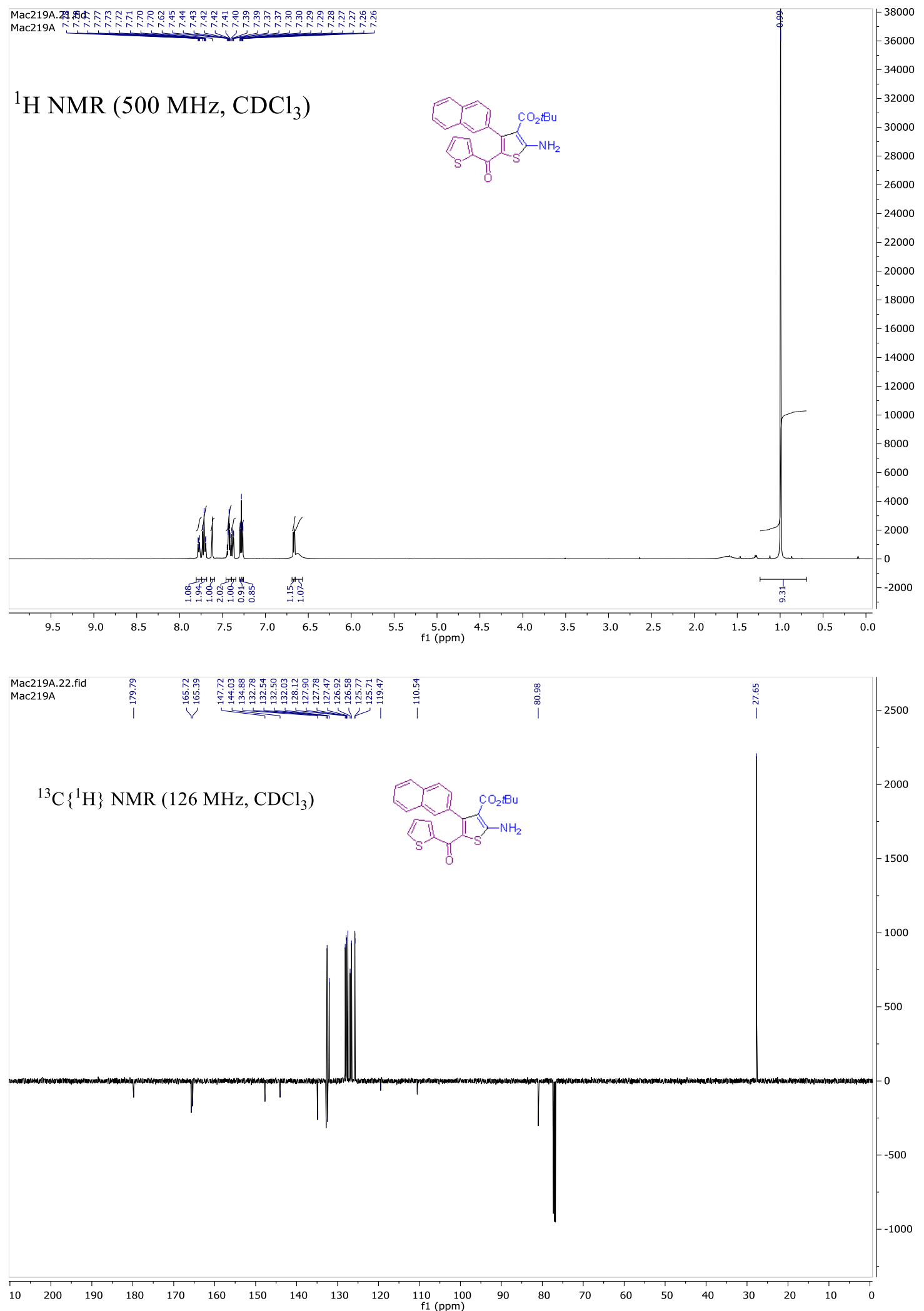
tert-Butyl 2-amino-4-(4-fluorophenyl)-5-(thiophene-2-carbonyl)thiophene-3-carboxylate (3xva)
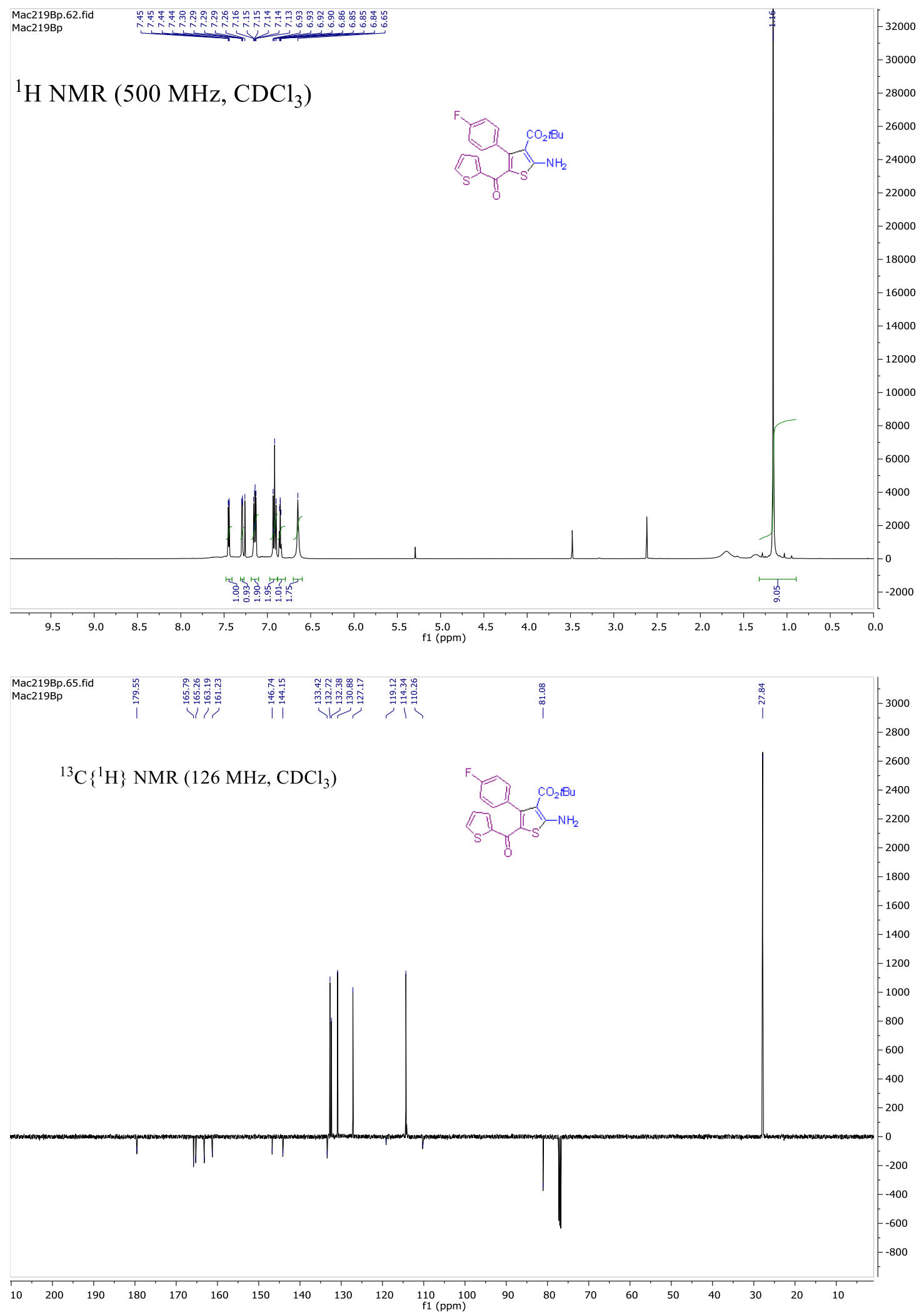


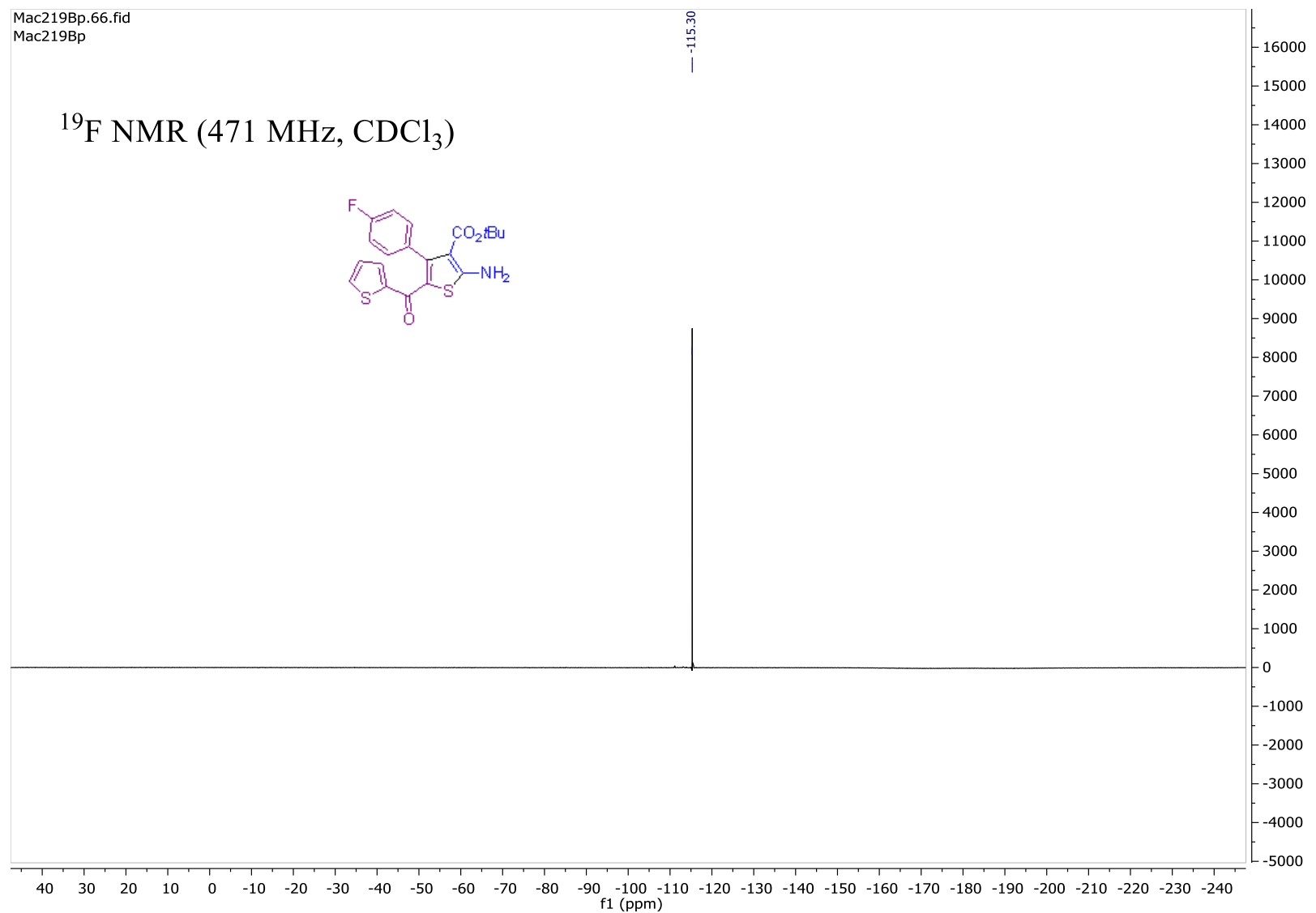


tert-Butyl 2-amino-4-(benzo[b]thiophen-2-yl)-5-(4-fluorobenzoyl)thiophene-3-carboxylate (3yxa)
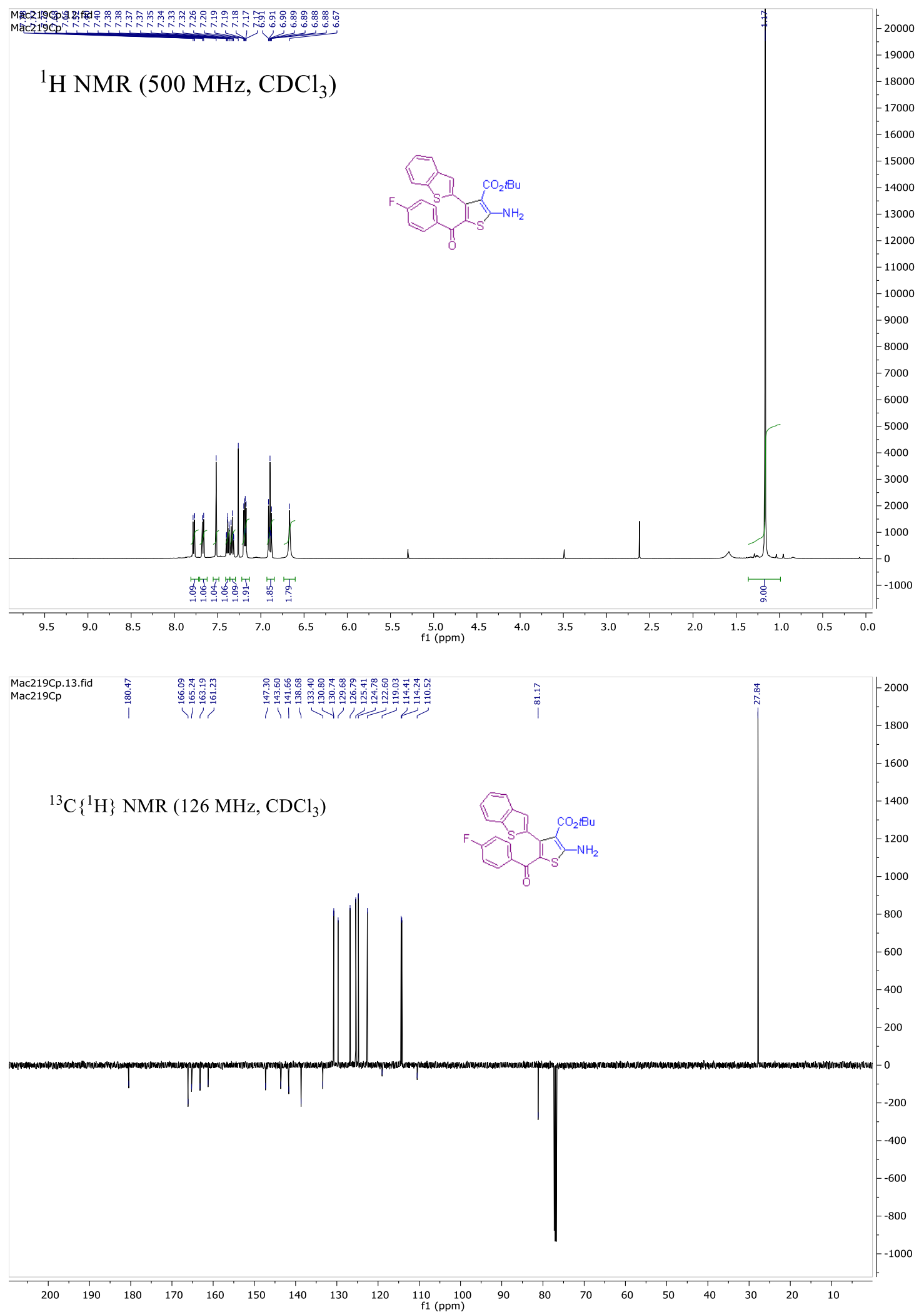


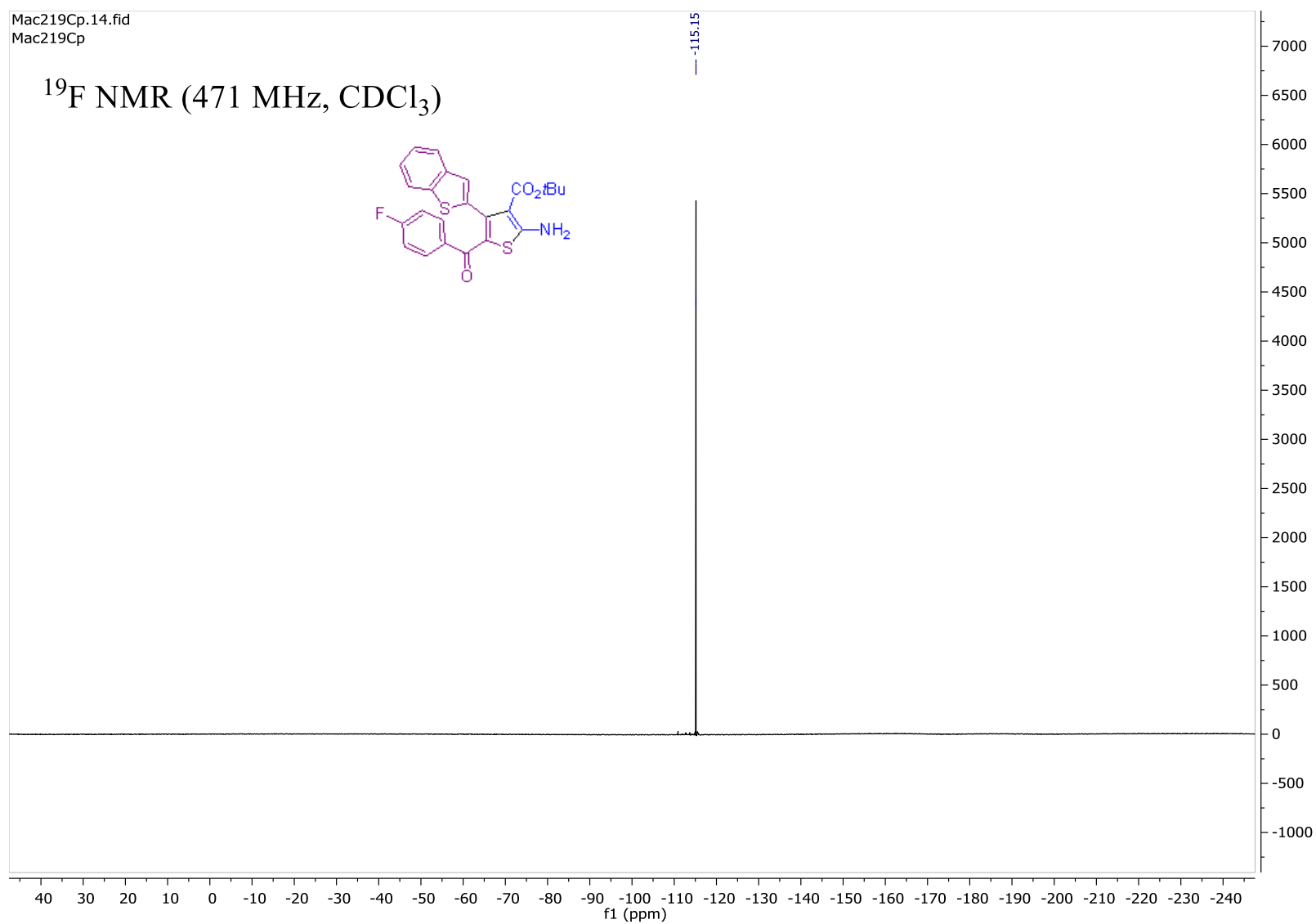


tert-Butyl 5-(2-naphthoyl)-2-amino-4-(4-fluorophenyl)thiophene-3-carboxylate (3axg)
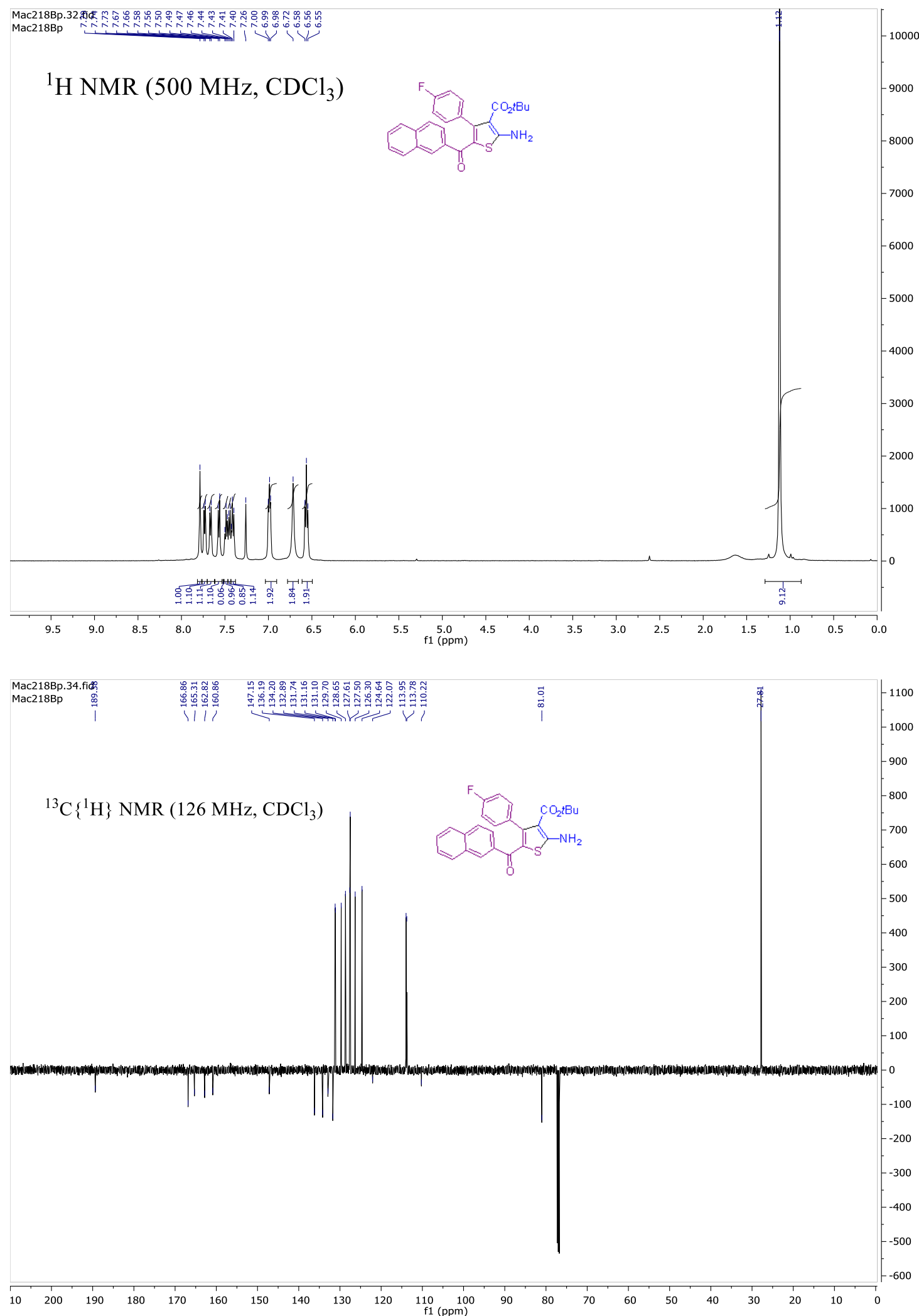


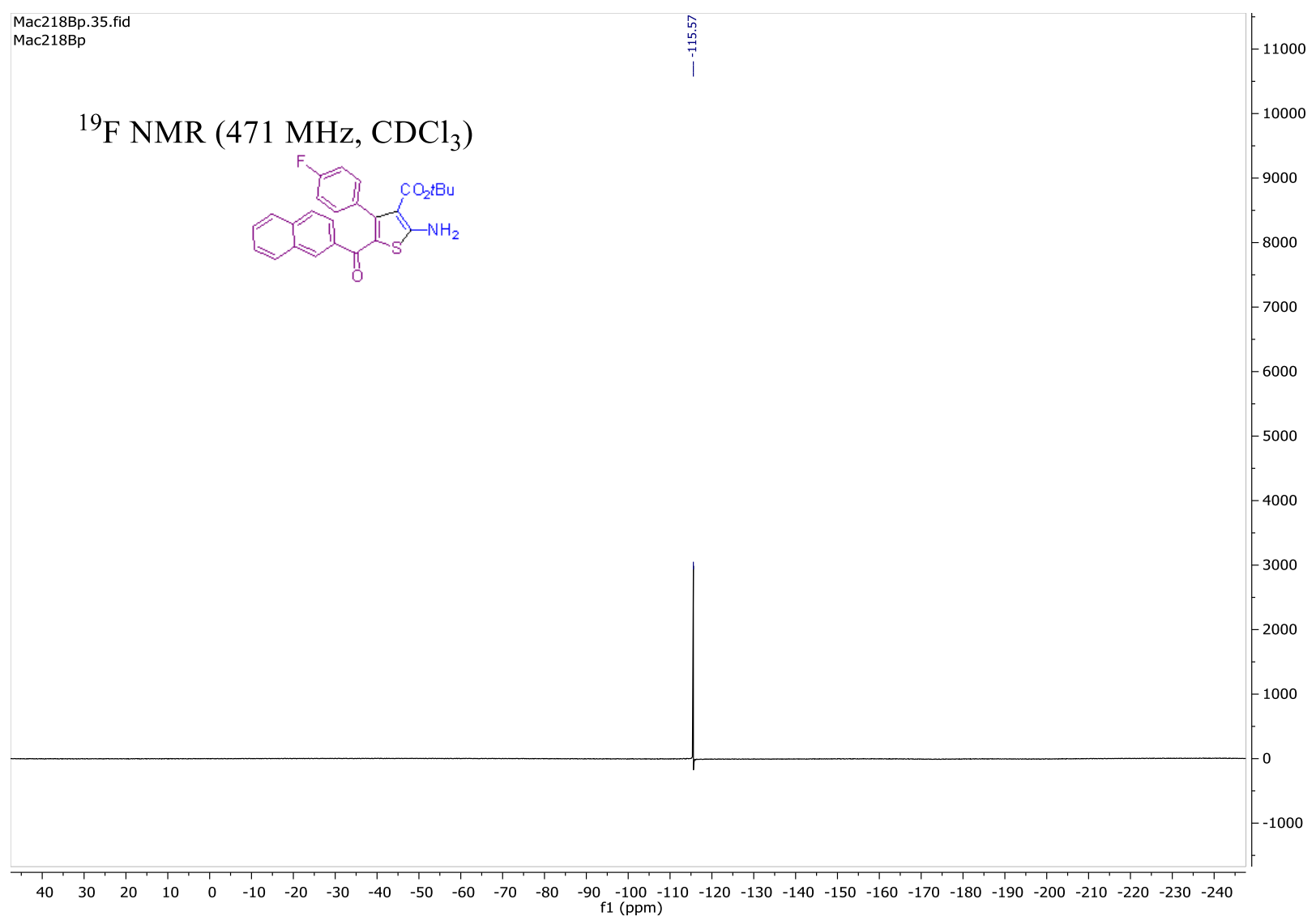


Di-tert-butyl 4,4'-(1,4-phenylene)bis(2-amino-5-benzoylthiophene-3-carboxylate) (3za)
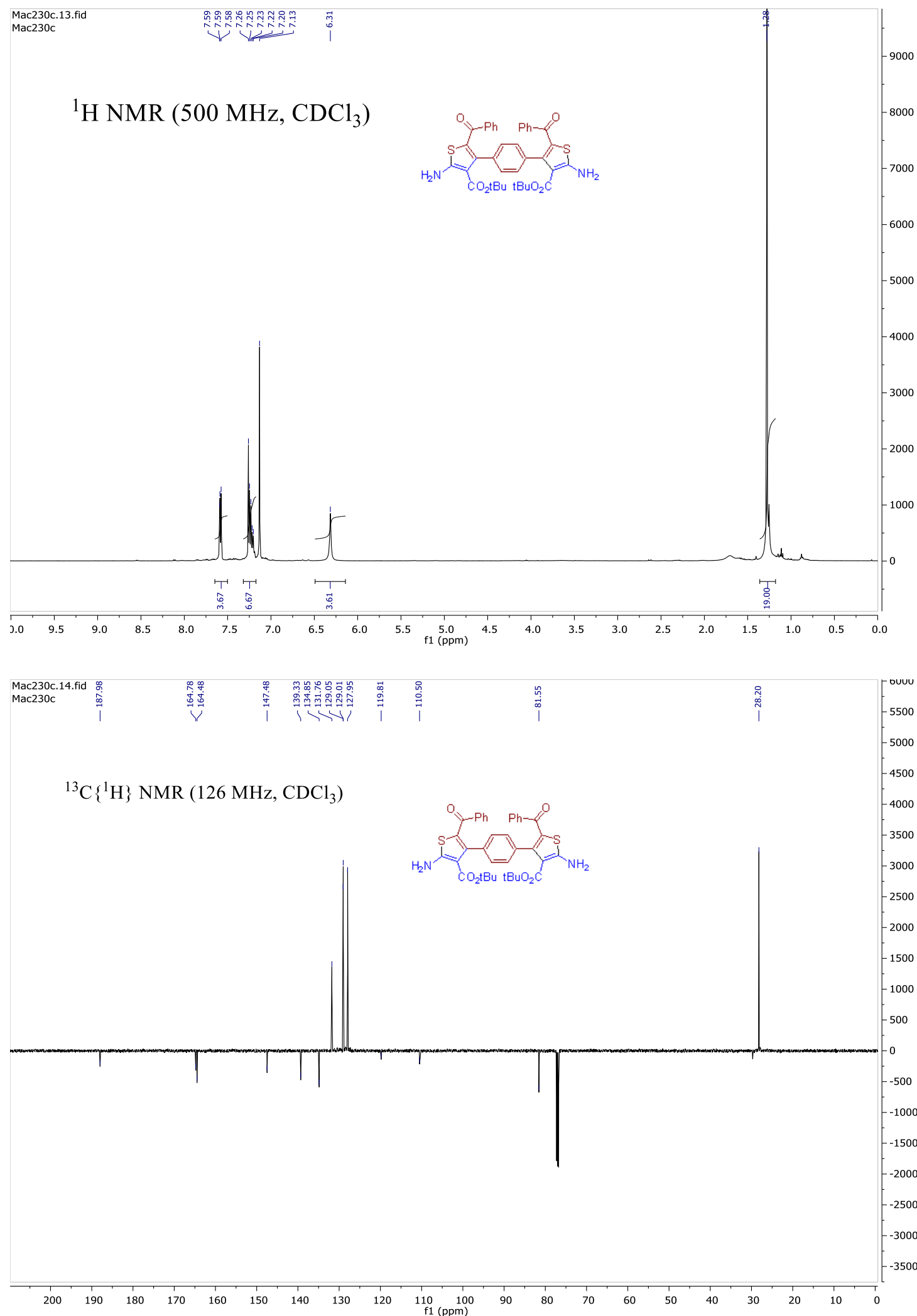
Butyl 2-amino-5-benzoyl-4-phenylthiophene-3-carboxylate (3aac)
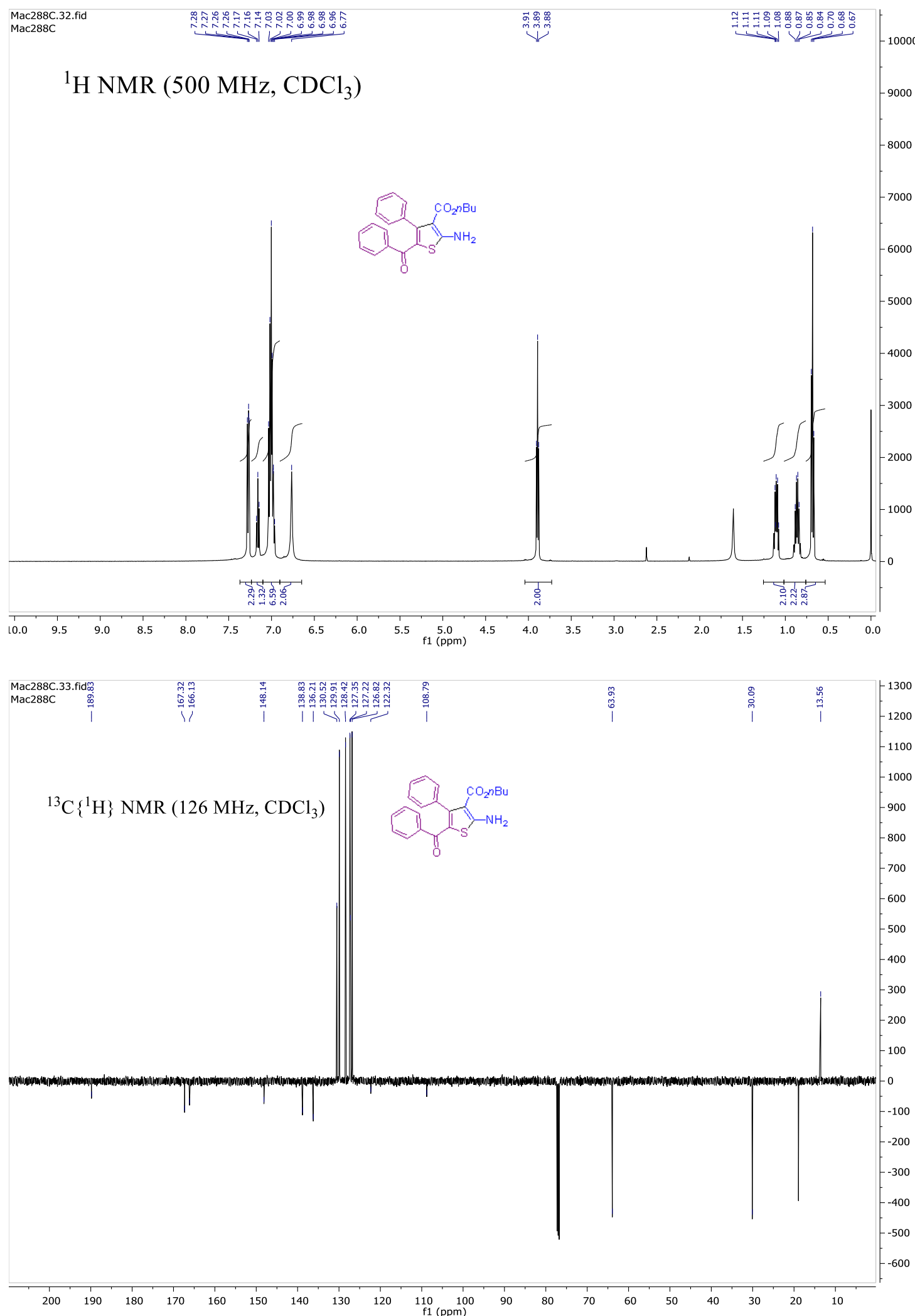
Isopropyl 2-amino-5-benzoyl-4-phenylthiophene-3-carboxylate (3aad)
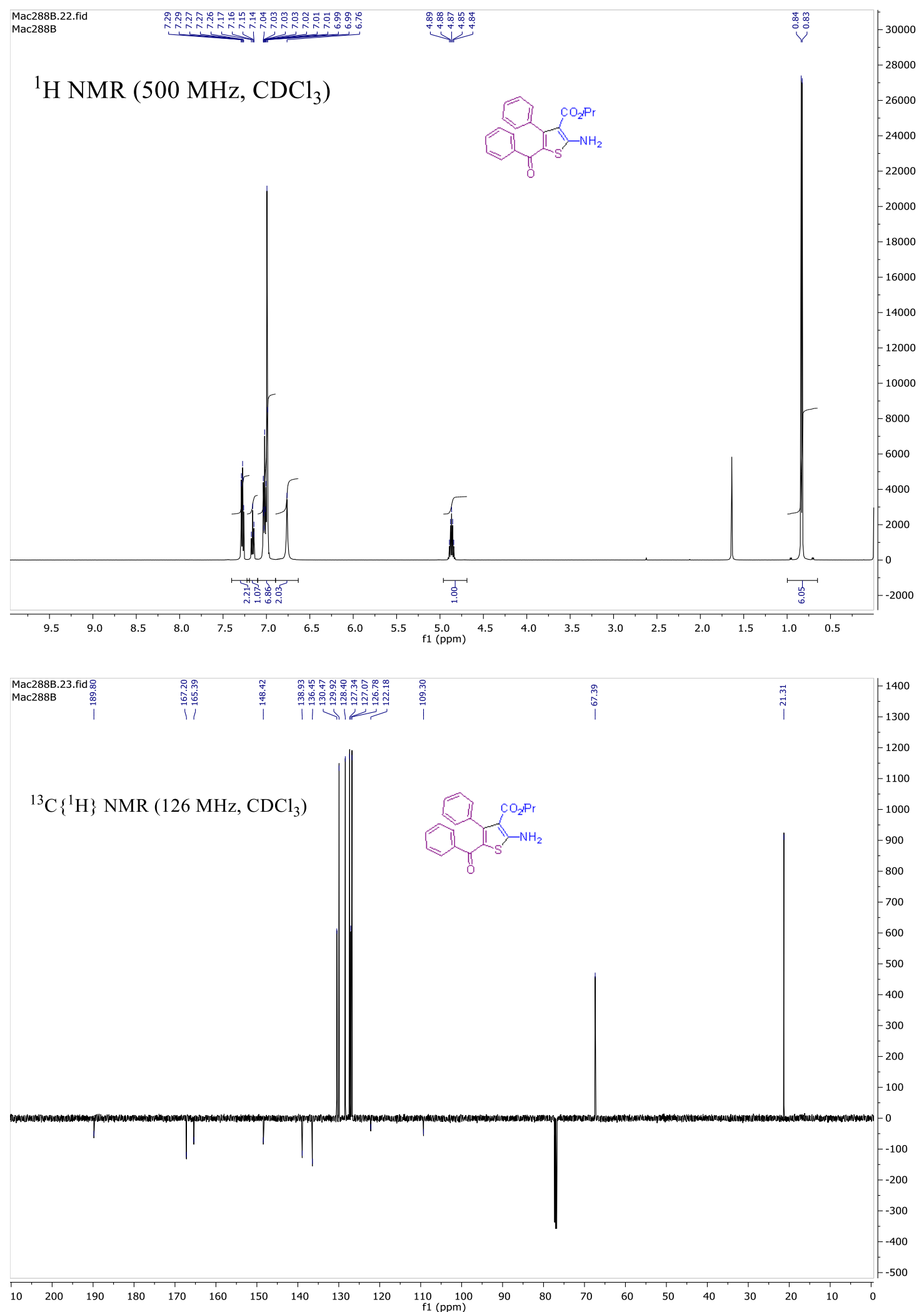
2-Amino-5-benzoyl-N-Butyl-4-phenylthiophene-3-carboxamide (3aae)
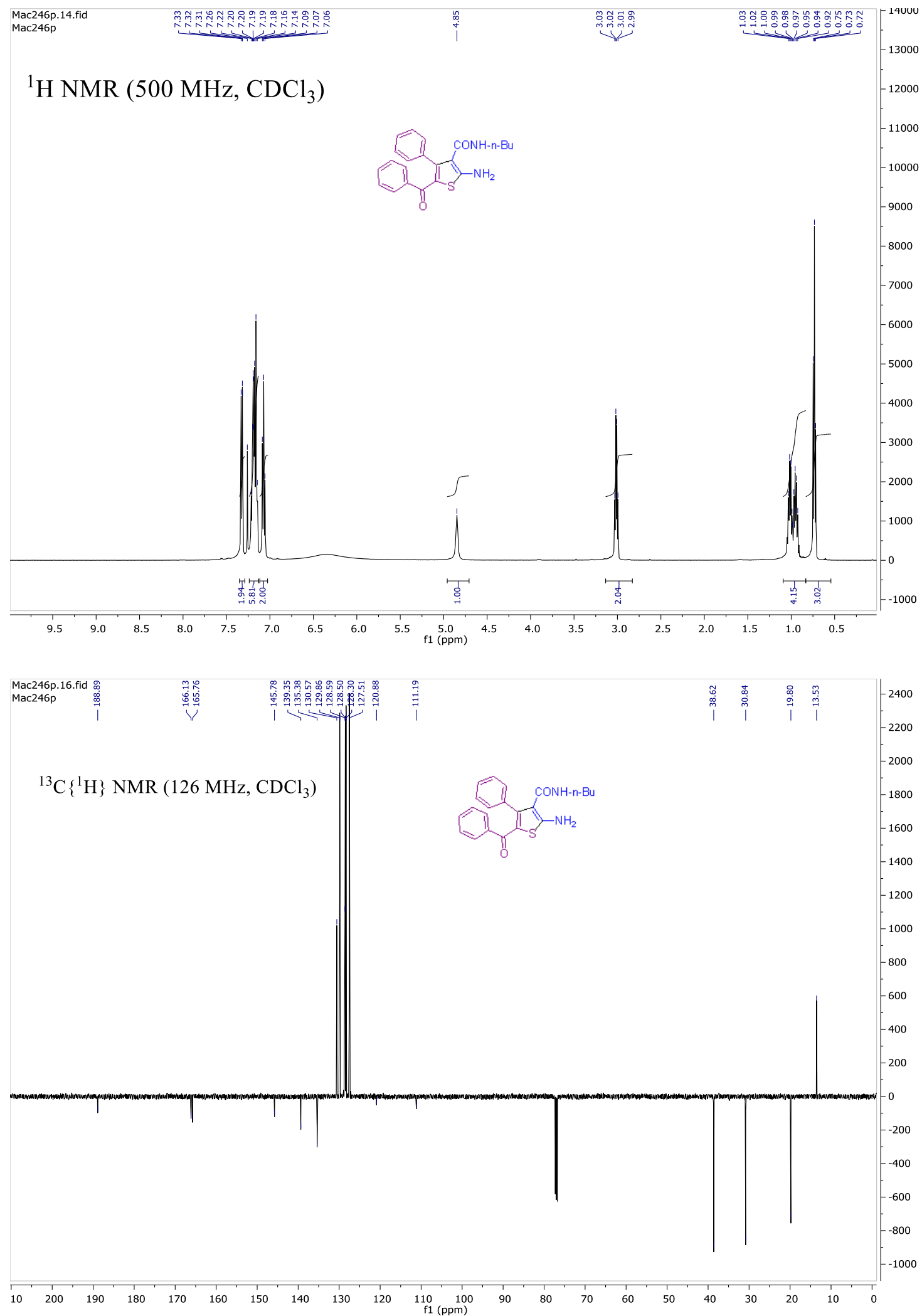
2-Amino-5-benzoyl-N-isopropyl-4-phenylthiophene-3-carboxamide (3aaf)
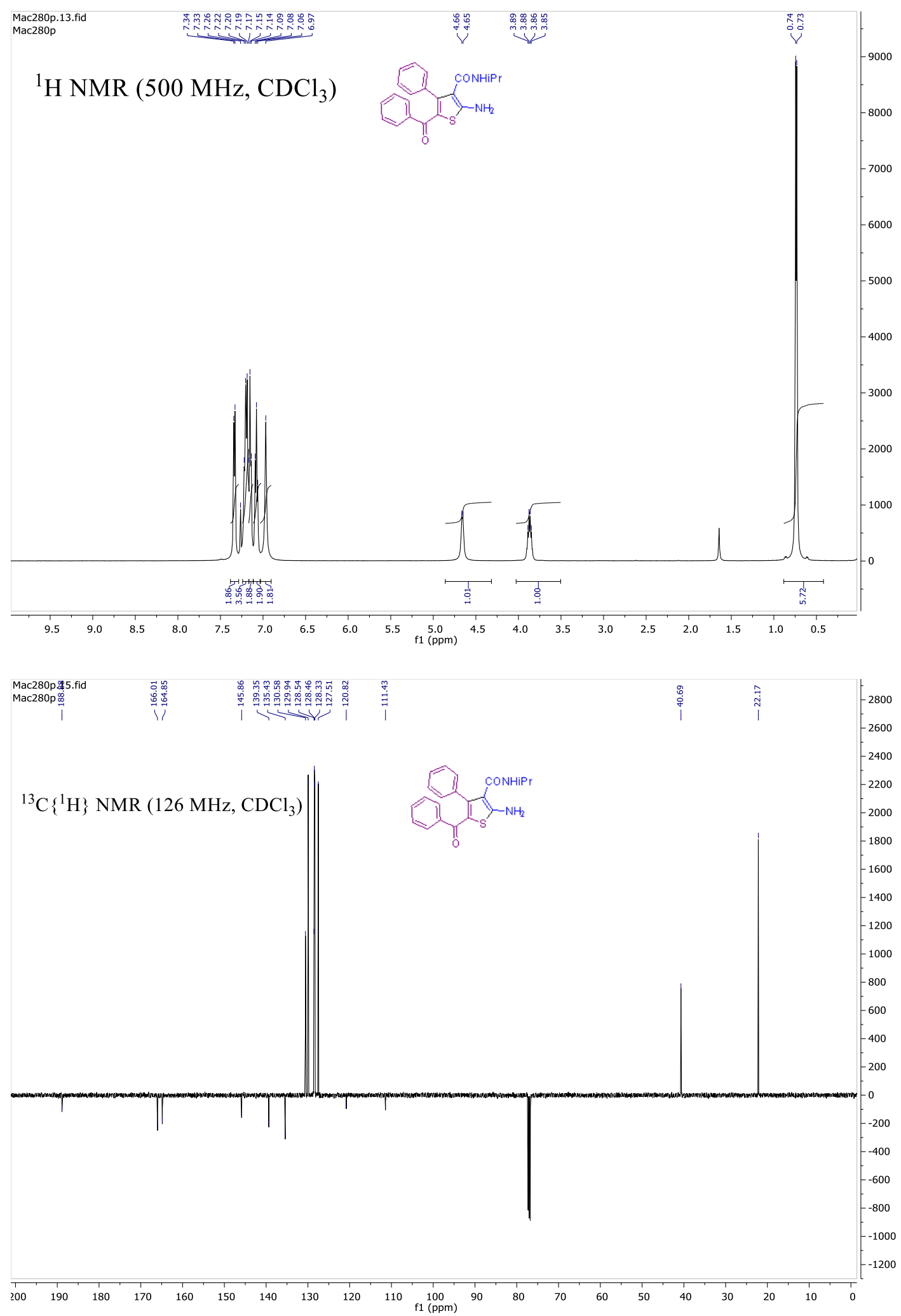


\section{2-Amino-5-benzoyl-N-benzyl-4-phenylthiophene-3-carboxamide (3aag)}

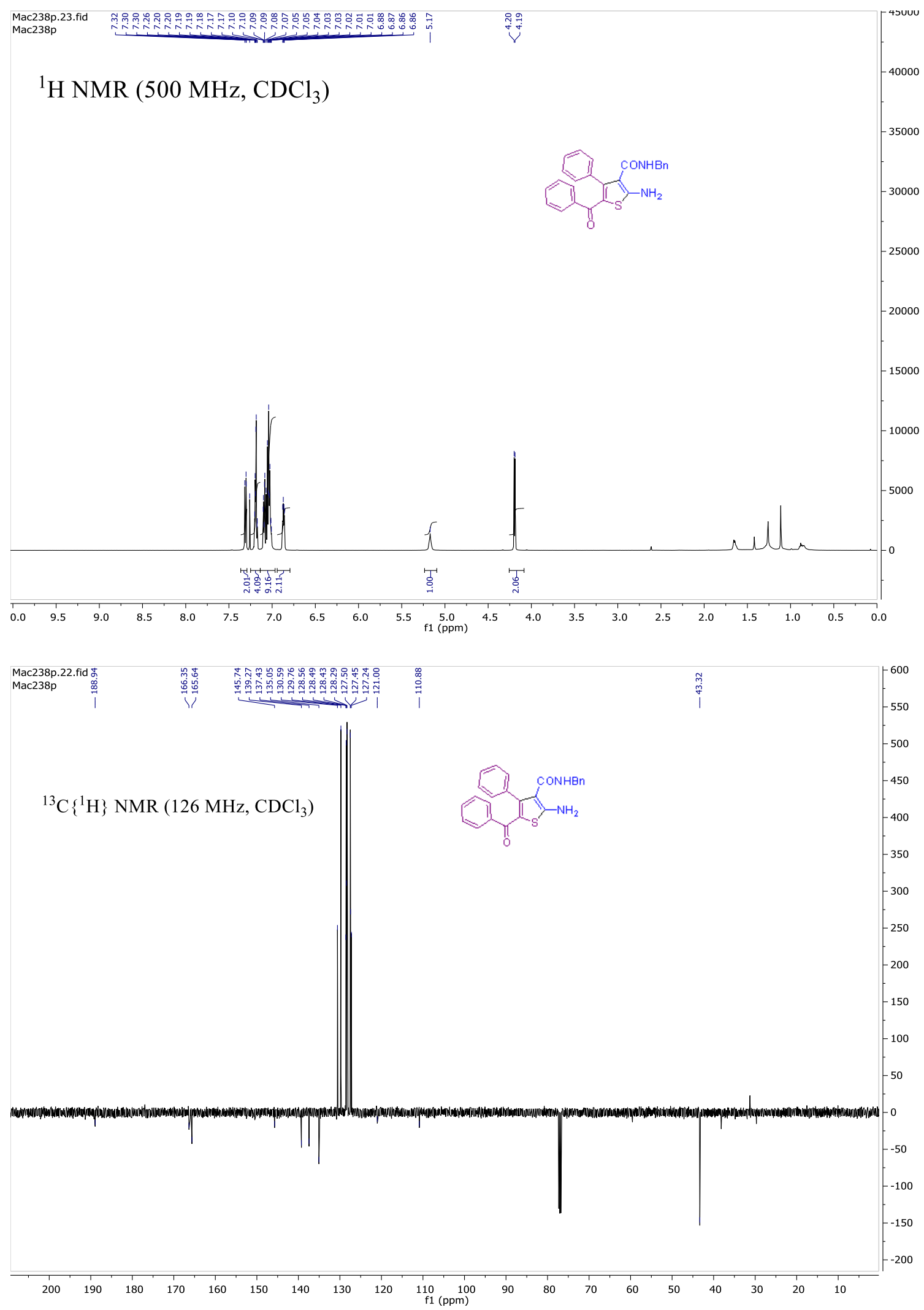




\section{(Z)-3-hydroxy-1,3-diphenylprop-2-en-1-one (C1) $1 \mathrm{H}$ NMR spectra in $\mathrm{CDCl}_{3}$ and $\mathrm{DMSO}_{6}$}

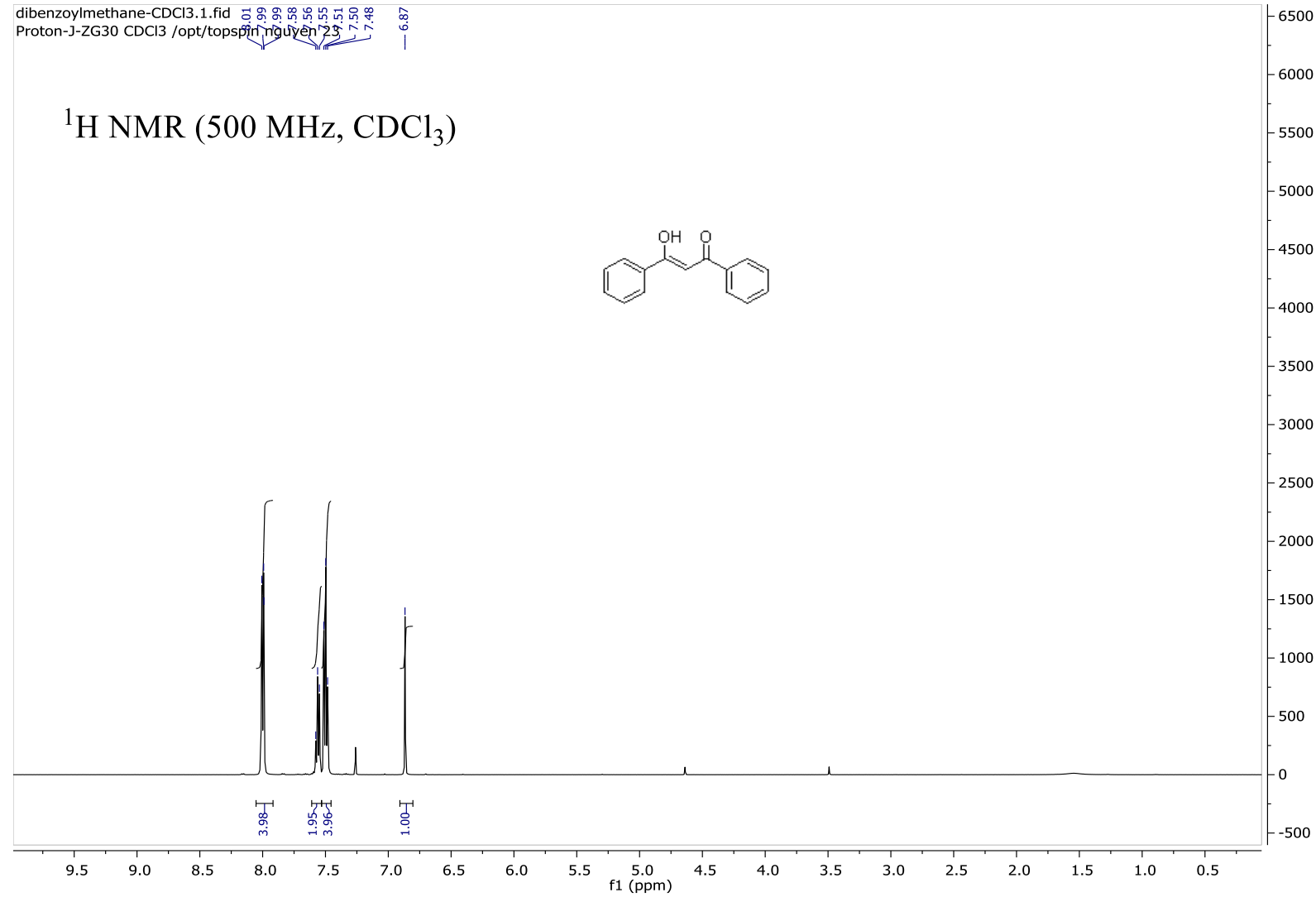

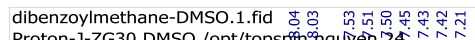

Proton-J-ZG30 DMSO /opt/topspingigureniz4

${ }^{1} \mathrm{H}$ NMR (500MHz, DMSO-d 6 )

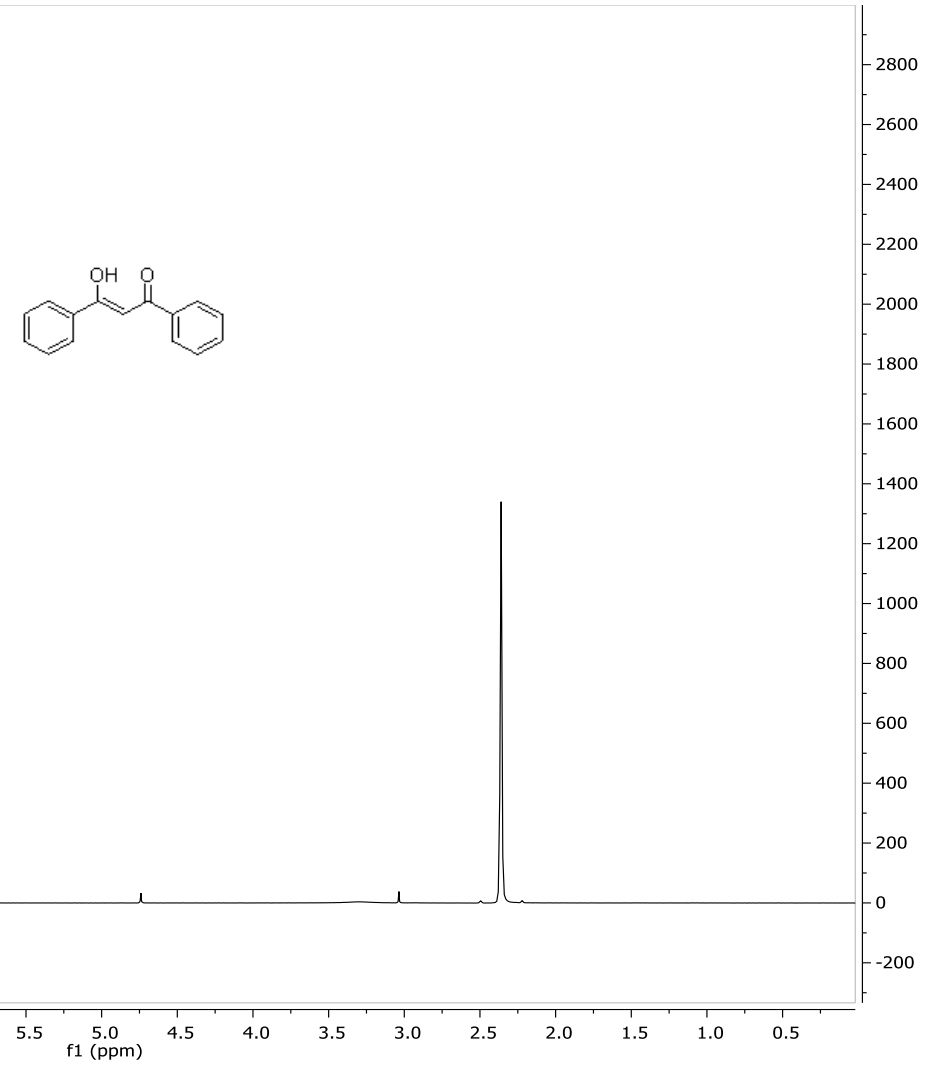

